\title{
Dux4 controls migration of mesenchymal stem cells through the Cxcr4-Sdf1 axis
}

\author{
Petr Dmitriev1,2,*, Ekaterina Kiseleva2,3,*, Olga Kharchenko ${ }^{2,3}$, Evgeny Ivashkin ${ }^{2,3}$, \\ Andrei Pichugin 2,3,7, Philippe Dessen ${ }^{4}$, Thomas Robert ${ }^{4}$, Frédérique Coppée ${ }^{5}$, \\ Alexandra Belayew5 ${ }^{5}$ Gilles Carnac ${ }^{6}$, Dalila Laoudj-Chenivesse $^{6}$, Marc Lipinski $^{1,2}$, \\ Andrei Vasiliev ${ }^{3}$, Yegor S. Vassetzky ${ }^{1,2,3}$ \\ ${ }^{1}$ UMR 8126, Univ. Paris-Sud, CNRS, Institut de Cancérologie Gustave-Roussy, Villejuif, France \\ ${ }^{2}$ LIA1066 Laboratoire Franco-Russe de Recherches en Oncologie, Villejuif, France \\ ${ }^{3}$ N.K. Koltzov Institute of Developmental Biology, RAS, Moscow, Russia \\ ${ }^{4}$ Functional Genomics Unit, Institut de Cancérologie Gustave-Roussy, Villejuif, France \\ ${ }^{5}$ Laboratory of Molecular Biology, Research Institute for Health Sciences and Technology, University of Mons, Mons, Belgium \\ ${ }^{6}$ PhyMedExp, University of Montpellier, INSERM U1046, CNRS UMR 9214, Montpellier, France \\ ${ }^{7}$ Peter the Great St. Petersburg Polytechnic University, St. Petersburg, Russia \\ *These authors contributed equally to this work
}

Correspondence to: Yegor S. Vassetzky, email: vassetzky@igr.fr

Keywords: DUX4, CXCR4, SDF1, signalling, migration

Received: April 01, $2016 \quad$ Accepted: August 10, $2016 \quad$ Published: August 18, 2016

\section{ABSTRACT}

We performed transcriptome profiling of human immortalized myoblasts (MB) transiently expressing double homeobox transcription factor 4 (DUX4) and double homeobox transcription factor 4 centromeric (DUX4c) and identified 114 and 70 genes differentially expressed in DUX4- and DUX4C-transfected myoblasts, respectively. A significant number of differentially expressed genes were involved in inflammation, cellular migration and chemotaxis suggesting a role for DUX4 and DUX4c in these processes. DUX4 but not $D U X 4 C$ overexpression resulted in upregulation of the CXCR4 (C-X-C motif Receptor 4) and CXCL12 (C-X-C motif ligand 12 also known as SDF1) expression in human immortalized myoblasts. In a Transwell cell migration assay, human bone marrow-derived mesenchymal stem cells (BMSCs) were migrating more efficiently towards human immortalized myoblasts overexpressing DUX4 as compared to controls; the migration efficiency of DUX4-transfected BMSCs was also increased. DUX4c overexpression in myoblasts or in BMSCs had no impact on the rate of BMSC migration. Antibodies against SDF1 and CXCR4 blocked the positive effect of DUX4 overexpression on BMSC migration. We propose that DUX4 controls the cellular migration of mesenchymal stem cells through the CXCR4 receptor.

\section{INTRODUCTION}

Human genome harbors 333 genes and pseudogenes with homeobox sequences encoding homeodomain DNA binding motif. Most of homeobox genes are transcription factors of which many are known to play key roles in animal development (for review see [1]). Among all homeobox genes, the double homeobox (DUX) family is one of the most enigmatic. DUX family members numbered from 1 to 5 [2-4] are encoded within tandem repeats of macrosatellite DNA and their multiple polymorphic copies are spread over human genome. Two other members of the DUX family, DUXA [5] and DUXB [6] are single-copy genes encoded on chromosome 19 and 16 , respectively.

Double homeobox protein 4 (DUX4) and its nearly identical homologue DUX4 centromeric (DUX4c) are the best known of all DUX proteins (for review see [7]). Multiple copies of DUX4 ORFs reside within $3.3 \mathrm{~kb}$-long macrosatellite repeats on chromosomes $4 \mathrm{q} 35$ and $10 \mathrm{q} 26$ also called D4Z4 $[8,3]$. The copy number of DUX4 ORF may vary from several units to several hundred making it 
the highest copy number ORF in human genome [9]. The single-copy of $D U X 4 \mathrm{c}$ gene is located $42 \mathrm{~kb}$ proximally to D4Z4 array on chromosome 4q35 [10].

The alternative splicing of $D U X 4$ pre-mRNA results in the production of either a full-length 424 amino acidlong or truncated 160-aa protein lacking the C-terminal transactivation domain (DUX4-s) [11-12]. High level of full-length DUX4 overexpression was shown to be toxic for mouse and human cultured cells [13-16]. In vivo, ubiquitous $D U X 4$ overexpression is detrimental for zebrafish [17] and Xenopus [18] development. Muscle-specific $D U X 4$ overexpression resulted in tissue deterioration $[19,18,20]$ specific overexpression in other tissues types was not tested. DUX4 toxicity has been linked to p53-dependent apoptosis induction [19, 13, 14, 19] and has been shown to require the $C$ terminus [15] and the integrity of DNA binding domains $[19,15]$ of DUX4. Other biological effects of DUX4 overexpression in vitro include an increased sensitivity to oxidative stress and an inhibition of myogenic differentiation of human and mouse myogenic progenitor cells [14, 21].

In contrast to DUX4, high level of DUX4c [22, 23] or DUX4-S [24] expression is not toxic for the cells in culture. DUX4c overexpression induced human myoblast proliferation [22] and inhibited myogenic differentiation [23]; phenotypic effects of $D U X 4-S$ overexpression were not described, however it has been shown to inhibit DUX4 target genes when overexpressed together with $D U X 4$ [12]. Neither ubiquitous nor muscle-specific $D U X 4 c$ expression in vivo interfered with embryogenesis or muscle tissue integrity in Xenopus [18]. Similarly, DUX4-s injection did not affect normal development of zebrafish embryos [20].

To better understand the mechanism of DUX4 impact on the cell, we performed transcriptome profiling of human primary myoblasts overexpressing full-length $D U X 4$ and $D U X 4 c$. One of the most striking findings of this analysis was an apparent upregulation of a significant number of chemokine genes. Chemokines is a superfamily of vertebrate-specific protein ligands interacting with rhodopsin-like G-protein-coupled receptors (GPCRs) [25]. The primary role of chemokines is the control of leukocyte traffic and recruitment to inflamed tissues (for review see [26-30]). Some of constitutively produced chemokines are known to play a role in processes unrelated to innate or acquired immunity (for review see [31-32]). Of these, CXCL12 (C-X-C motif ligand 12), also known as Stromalderived factor 1 (SDF1) [33]) and its primary receptor CXCR4 (C-X-C motif Receptor 4) [34] clearly stand apart due to an important role in development regulation [35], hematopoiesis, angiogenesis [36-37], stem cell migration [38] and wound healing (reviewed in [39-40]). In addition, CXCR4 is one of the major GPCR receptors controlling the migration of various cell types including leukocytes, HSPC, MSC (reviewed in [41].

MSC (mesenchymal stem or mesenchymal stromal cells) are multipotent stem cells capable of differentiation into chondrocytes, osteocytes, adipocytes and, more controversially, to other cell types (for review see [42]). The primary site of MSC localization is bone marrow, although cells with similar properties were also found in other tissues (for review see [43]). In adult organism, MSC are thought to contribute to tissue homeostasis. Tissue damage results in MSC mobilization from bone marrow and their homing to damaged tissue where they either differentiate to replenish damaged cells, stimulate differentiation of the tissue-resident stem cells, stimulate vascularization and control inflammation thus restoring the damage (reviewed in [44]). CXCR4-SDF1 signaling is known to be required for MSC homing and retention to their niche in bone marrow (for review see [43]) and has also been shown to stimulate MSC cell migration in vitro $[45,46]$. We have shown that $D U X 4$ overexpression results in upregulation of $C X C R 4$ and $S D F 1$ genes in several cell types and stimulates the migration of BMSC in a CXCR4and SDF1-dependent manner. Our results thus establish DUX4 as a novel regulator of cell mobility.

\section{RESULTS}

\section{Transcriptome profiling of $D U X 4$ - and $D U X 4 c$ - overexpressing human myoblasts}

Several transcriptomic studies have been performed on cells overexpressing $D U X 4$, at the same time its homologue $D U X 4 c$ is much less studied. We argued that the difference in transcriptome profiles of DUX4 and $D U X 4 c$ might help us to better understand the functional differences between these two proteins. We thus performed transcriptome profiling of $D U X 4$ - and $D U X 4 c$ - transfected immortalized human myoblasts (MB) at two time points (12 and $24 \mathrm{~h}$ ) following transfection. Overall, we have identified 130 differentially expressed genes of which 60 genes were differentially expressed only in DUX4transfected cells, 16 genes only in $D U X 4 c$ transfected cells and 54 genes were differentially expressed both in DUX4- and DUX4c-transfected cells (Figure 1). With rare exceptions, all significantly overexpressed DUX4 target genes found in our study were already described previously [12] (Tables 1-4 and Supplementary Table S1). DUX4 is known to induce apoptosis in various cell types including human myoblasts. Indeed, we observed a significant induction of apoptosis and cell mortality in DUX4-transfected MB $72 \mathrm{~h}$ after the transfection (data not shown). However, $24 \mathrm{~h}$ after the transfection, apoptosis and cell mortality were significantly increased neither in $D U X 4$ - nor in $D U X 4 c$-transfected MB indicating that our transcriptomic data obtained at earlier time points may contain information about other functional activities of DUX4 (Supplementary Figure S1).

According to GeneOntology analysis, significant known functions of the majority of genes differentially expressed in $D U X 4$ and $D U X 4 c$-overexpressing myoblasts 
included inflammation, chemotaxis, metabolism and apoptosis (Figure 2 and Supplementary Table S2). These functional categories have already been attributed to DUX4 target genes in previous transcriptomic studies of genes differentially expressed in $D U X 4$-overexpressing

A

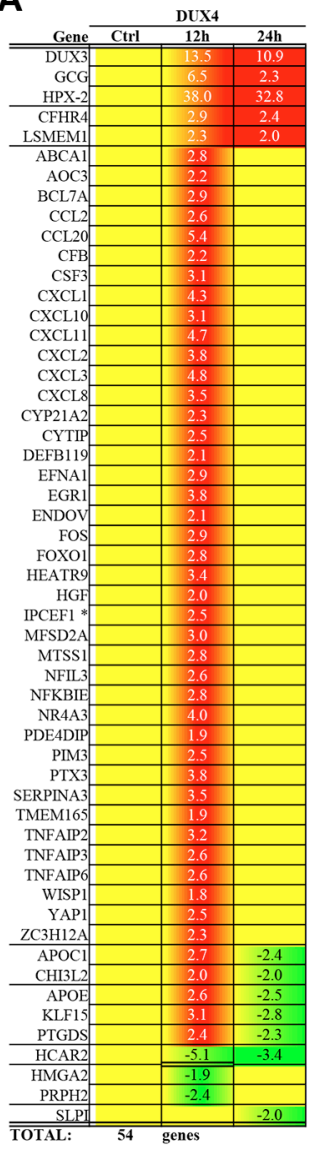

* IPCEFI probe also corresponds to CNKSR3 gene

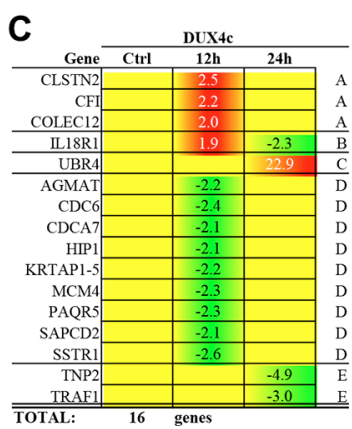

murine C2C12 myoblasts [14], human primary myoblasts [12] and rhabdomyosarcoma cells [47]; furthermore, functional involvement of ectopically expressed $D U X 4$ in certain aspects of cellular metabolism and regulation of apoptosis has been previously demonstrated $[13,14]$.

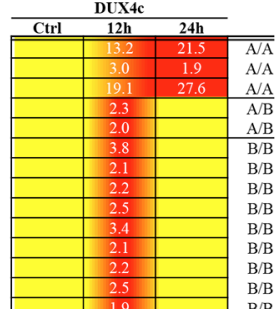
$A / A$
$A / A$
$A / A$
$A B B$
$A B B$
$B B B$
$B B$
$B / B$
$B / B$
$B / B$
$B / B$
$B / B$
$B / B$
$B / B$
$B / B$

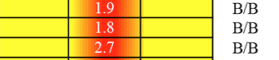

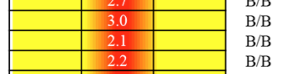

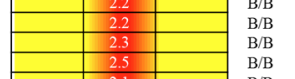
\begin{tabular}{|l|l|l|l}
\hline & 2.1 & & $\mathrm{~B} / \mathrm{B}$ \\
$\mathrm{B} / \mathrm{B}$ \\
$\mathrm{B} / \mathrm{B}$ \\
$\mathrm{B} / \mathrm{B}$ \\
\hline
\end{tabular} \begin{tabular}{|l|l|l|l|} 
& 2.4 & $\mathrm{~B} / \mathrm{B}$ \\
$\mathrm{B} / \mathrm{B}$ \\
$\mathrm{B} / \mathrm{B}$ \\
$\mathrm{B} / \mathrm{B}$ \\
$\mathrm{B} / \mathrm{B}$ \\
\hline
\end{tabular}

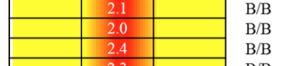

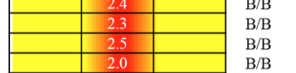

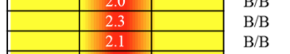

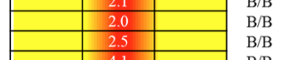

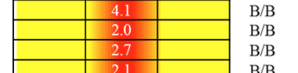

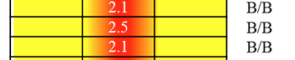

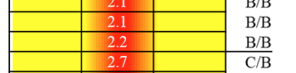

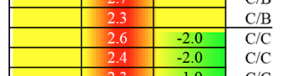

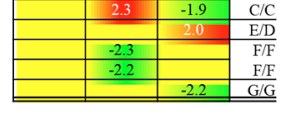
西

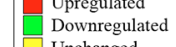
Unchanged
B

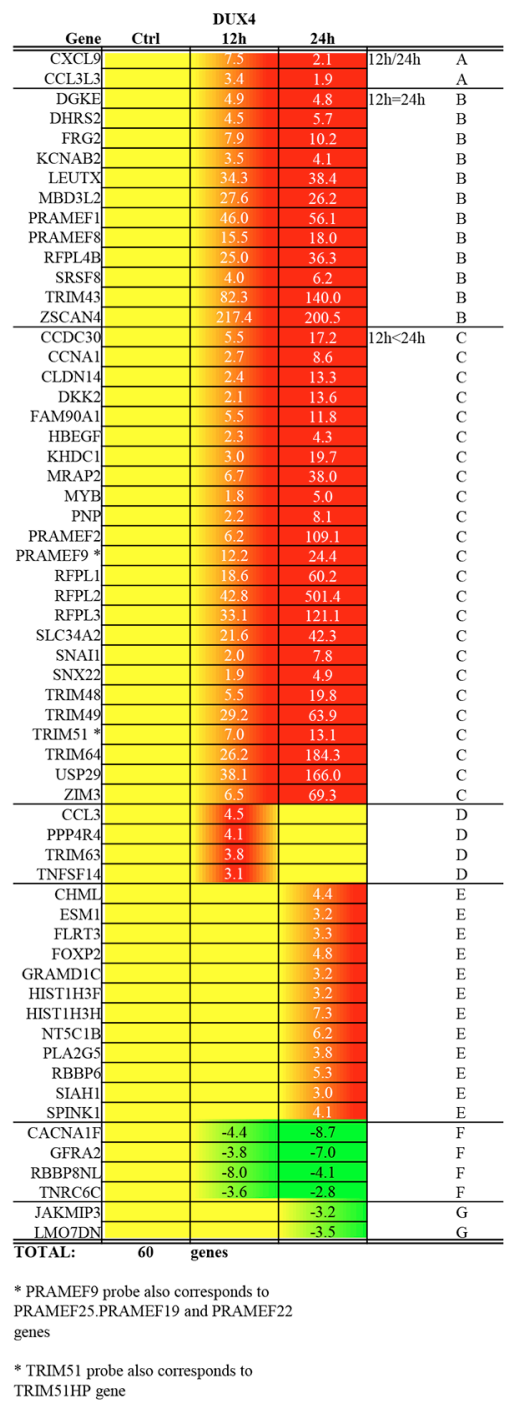

Figure 1: Genes differentially expressed 12- and $24 \mathrm{~h}$ after the transfection of human immortalized myoblasts (MB) with DUX4 or DUX4c plasmids as compared to empty vector; yellow: no differential expression $(-1.5<\mathrm{FC}<1.5)$; red: upregulated (FC > 1.5); green: downregulated (FC $<-1.5)$. (A) Genes differentially expressed in both DUX4- and DUX4ctransfected MB; genes upregulated at both $12 \mathrm{~h}$ and $24 \mathrm{~h}$, only at $12 \mathrm{~h}$ or $24 \mathrm{~h}$ time-points are labeled with (A, B and D) respectively; genes upregulated at $12 \mathrm{~h}$ but downregulated at $24 \mathrm{~h}$ time-point are labeled with C; genes downregulated at both $12 \mathrm{~h}$ and $24 \mathrm{~h}$, only at 12 $\mathrm{h}$ or $24 \mathrm{~h}$ time-points are labeled with (E, F and G) respectively. (B) Genes differentially expressed only in DUX4-transfected MB; genes upregulated at both $12 \mathrm{~h}$ and $24 \mathrm{~h}$ time-points with the expression level at $12 \mathrm{~h}$ higher, equal or lower than at $24 \mathrm{~h}$ are labeled with (A, B or C) respectively; genes upregulated only at $12 \mathrm{~h}$ or $24 \mathrm{~h}$ time-points are labeled with $\mathrm{D}$ and E respectively; genes downregulated at both time-points or only at $24 \mathrm{~h}$ time-point are labeled with $\mathrm{F}$ and $\mathrm{G}$ respectively. (C) Genes differentially expressed only in DUX4c-transfected MB; genes upregulated at $12 \mathrm{~h}$ or $24 \mathrm{~h}$ or downregulated at $12 \mathrm{~h}$ or $24 \mathrm{~h}$ time-points are labeled with A, C, D and E respectively; genes upregulated at $12 \mathrm{~h}$ but downregulated at $24 \mathrm{~h}$ time-points are labeled with B. 
Table 1: Genes differentially expressed in hIMB cells $12 \mathrm{~h}$ after DUX4-plasmid transfection

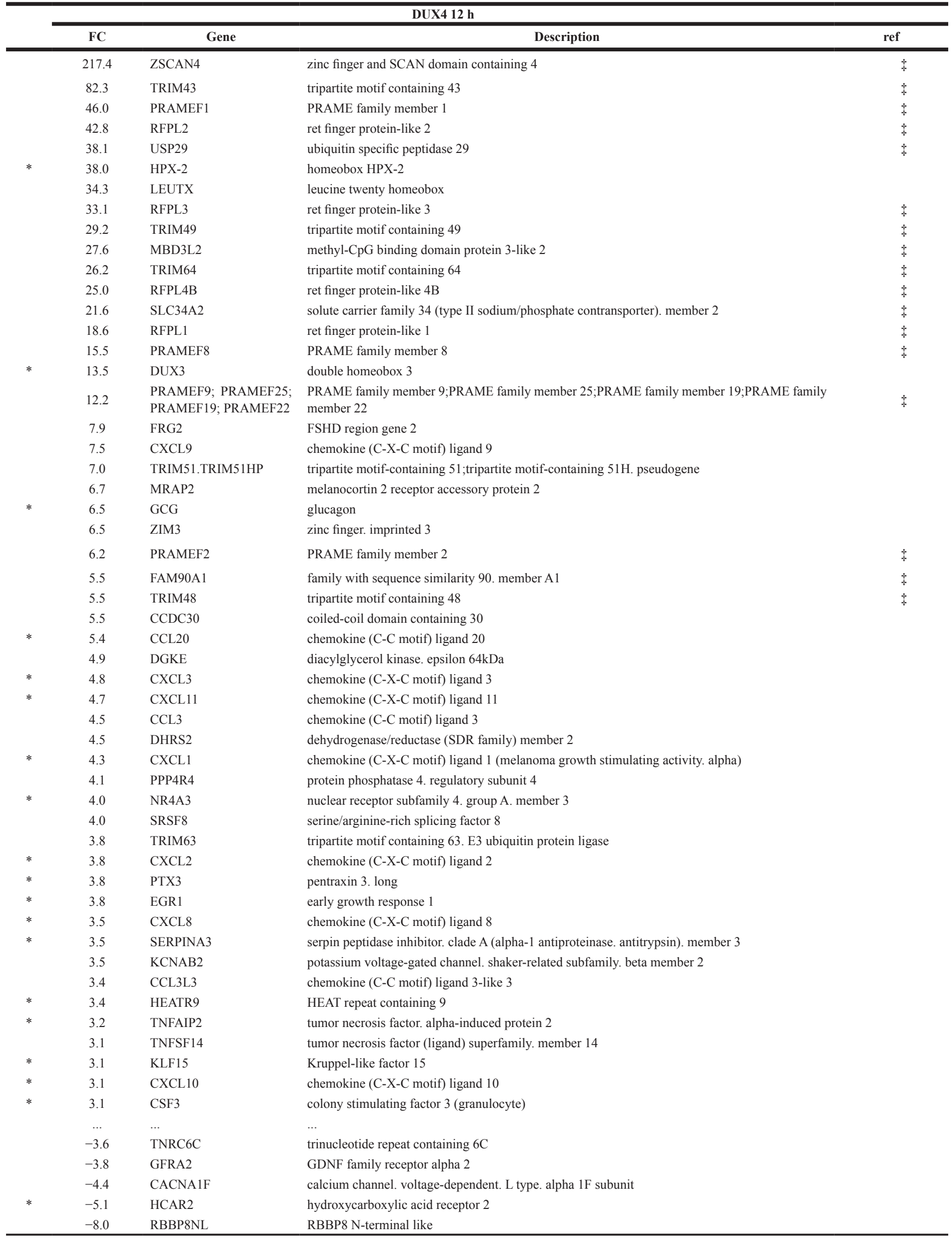

Asterisk labels genes that are also differentially expressed in DUX4c-transfected IMBs. $\ddagger$ labels genes previously descried DUX4 target genes [12]. 
Table 2: Genes differentially expressed in hIMB cells $24 \mathrm{~h}$ after DUX4-plasmid transfection

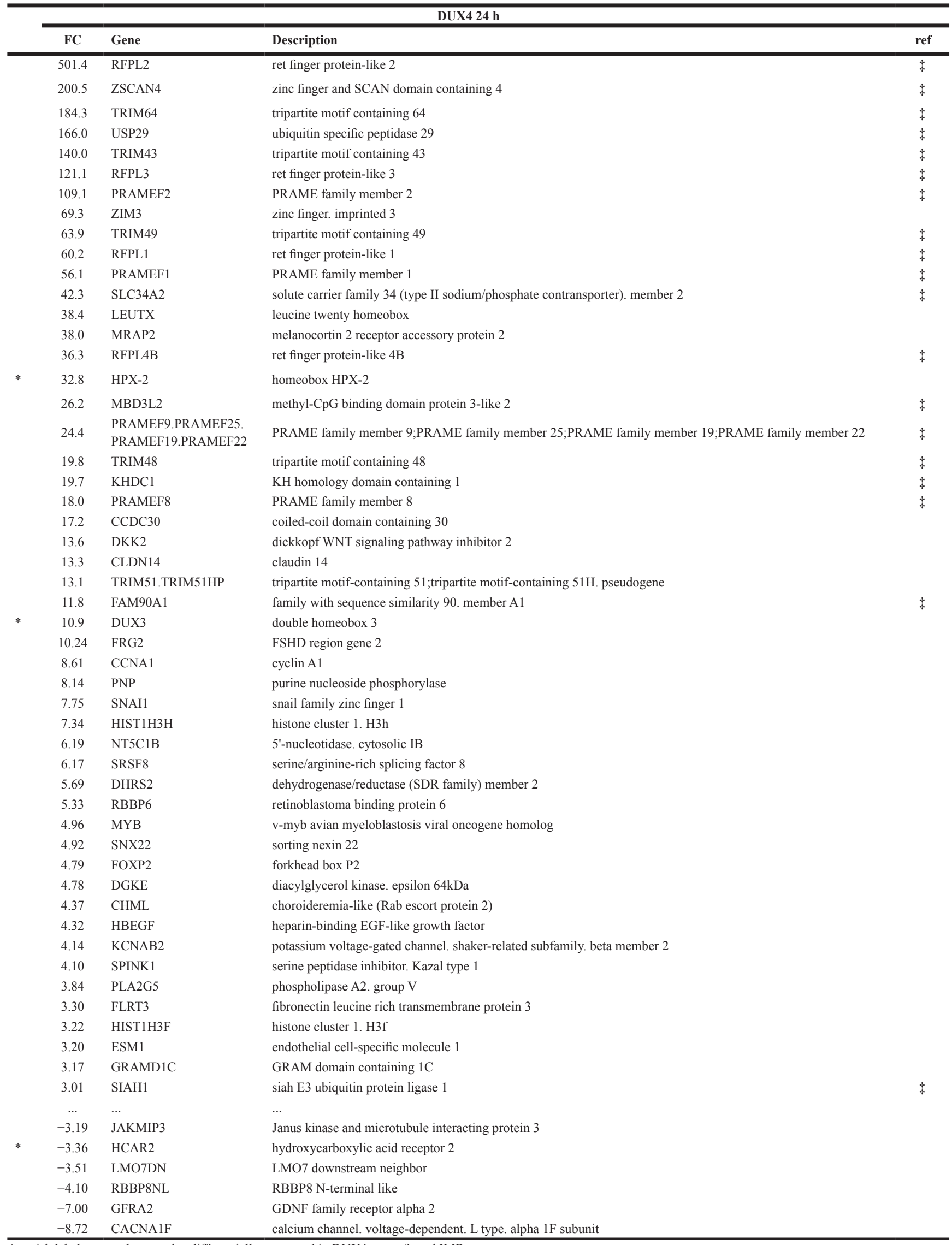

Asterisk labels genes that are also differentially expressed in DUX4c-transfected IMBs. 
Table 3: Genes differentially expressed in hIMB cells $12 \mathrm{~h}$ after DUX4c-plasmid transfection

DUX4c $12 \mathrm{~h}$

\begin{tabular}{|c|c|c|c|}
\hline & FC & Gene & Description \\
\hline$*$ & 19.1 & HPX-2 & homeobox HPX-2 \\
\hline$*$ & 13.2 & DUX3 & double homeobox 3 \\
\hline$*$ & 4.1 & SERPINA3 & serpin peptidase inhibitor. clade A (alpha-1 antiproteinase. antitrypsin). member 3 \\
\hline$*$ & 3.8 & ABCA1 & ATP-binding cassette. sub-family A (ABC1). member 1 \\
\hline$*$ & 3.4 & CCL20 & chemokine (C-C motif) ligand 20 \\
\hline$*$ & 3.0 & GCG & glucagon \\
\hline$*$ & 3.0 & CXCL3 & chemokine (C-X-C motif) ligand 3 \\
\hline$*$ & 2.7 & CXCL2 & chemokine (C-X-C motif) ligand 2 \\
\hline$*$ & 2.7 & TNFAIP2 & tumor necrosis factor. alpha-induced protein 2 \\
\hline$*$ & 2.7 & APOC1 & apolipoprotein C-I \\
\hline$*$ & 2.6 & APOE & apolipoprotein $\mathrm{E}$ \\
\hline \multirow[t]{2}{*}{$*$} & 2.6 & MFSD2A & major facilitator superfamily domain containing $2 \mathrm{~A}$ \\
\hline & 2.5 & CLSTN2 & calsyntenin 2 \\
\hline$*$ & 2.5 & HEATR9 & HEAT repeat containing 9 \\
\hline$*$ & 2.5 & EFNA1 & ephrin-A1 \\
\hline$*$ & 2.5 & CCL2 & chemokine (C-C motif) ligand 2 \\
\hline$*$ & 2.5 & CXCL1 & chemokine (C-X-C motif) ligand 1 (melanoma growth stimulating activity. alpha) \\
\hline$*$ & 2.5 & TNFAIP6 & tumor necrosis factor. alpha-induced protein 6 \\
\hline$*$ & 2.5 & NFIL3 & nuclear factor. interleukin 3 regulated \\
\hline$*$ & 2.5 & PTX3 & pentraxin 3. long \\
\hline$*$ & 2.4 & FOXO1 & forkhead box $\mathrm{O} 1$ \\
\hline$*$ & 2.4 & KLF15 & Kruppel-like factor 15 \\
\hline$*$ & 2.4 & FOS & FBJ murine osteosarcoma viral oncogene homolog \\
\hline$*$ & 2.3 & NR4A3 & nuclear receptor subfamily 4 . group A. member 3 \\
\hline$*$ & 2.3 & CHI3L2 & chitinase 3 -like 2 \\
\hline$*$ & 2.3 & MTSS1 & metastasis suppressor 1 \\
\hline$*$ & 2.3 & DEFB119 & defensin. beta 119 \\
\hline$*$ & 2.3 & CFHR4 & complement factor H-related 4 \\
\hline$*$ & 2.3 & PTGDS & prostaglandin $\mathrm{D} 2$ synthase $21 \mathrm{kDa}$ (brain) \\
\hline$*$ & 2.2 & CSF3 & colony stimulating factor 3 (granulocyte) \\
\hline$*$ & 2.2 & CYTIP & cytohesin 1 interacting protein \\
\hline \multirow[t]{2}{*}{$*$} & 2.2 & BCL7A & B-cell CLL/lymphoma 7A \\
\hline & 2.2 & CFI & complement factor I \\
\hline$*$ & 2.2 & CYP21A2 & cytochrome P450. family 21 . subfamily A. polypeptide 2 \\
\hline$*$ & 2.2 & $\mathrm{ZC} 3 \mathrm{H} 12 \mathrm{~A}$ & zinc finger $\mathrm{CCCH}$-type containing $12 \mathrm{~A}$ \\
\hline$*$ & 2.1 & CXCL8 & chemokine (C-X-C motif) ligand 8 \\
\hline$*$ & 2.1 & PDE4DIP & phosphodiesterase 4D interacting protein \\
\hline$*$ & 2.1 & CFB & complement factor B \\
\hline$*$ & 2.1 & HGF & hepatocyte growth factor (hepapoietin A; scatter factor) \\
\hline$*$ & 2.1 & WISP1 & WNT1 inducible signaling pathway protein 1 \\
\hline$*$ & 2.1 & EGR1 & early growth response 1 \\
\hline \multirow[t]{2}{*}{$*$} & 2.1 & YAP1 & Yes-associated protein 1 \\
\hline & 2.1 & AOC3 & amine oxidase. copper containing 3 \\
\hline$*$ & 2.1 & TNFAIP3 & tumor necrosis factor. alpha-induced protein 3 \\
\hline$*$ & 2.1 & ENDOV & endonuclease $\mathrm{V}$ \\
\hline$*$ & 2.0 & PIM3 & Pim-3 proto-oncogene. serine/threonine kinase \\
\hline$*$ & 2.0 & NFKBIE & nuclear factor of kappa light polypeptide gene enhancer in B-cells inhibitor. epsilon \\
\hline$*$ & 2.0 & IPCEF1; CNKSR3 & interaction protein for cytohesin exchange factors 1 ; CNKSR family member 3 \\
\hline$*$ & 2.0 & LSMEM1 & leucine-rich single-pass membrane protein 1 \\
\hline \multirow[t]{6}{*}{$*$} & 2.0 & TMEM165 & transmembrane protein 165 \\
\hline & 2.0 & COLEC12 & collectin sub-family member 12 \\
\hline & $\ldots$ & $\ldots$ & $\ldots$ \\
\hline & -2.1 & HIP1 & huntingtin interacting protein 1 \\
\hline & -2.1 & SAPCD2 & suppressor APC domain containing 2 \\
\hline & -2.1 & CDCA7 & cell division cycle associated 7 \\
\hline \multirow[t]{3}{*}{ * } & -2.2 & PRPH2 & peripherin 2 (retinal degeneration. slow) \\
\hline & -2.2 & AGMAT & agmatine ureohydrolase (agmatinase) \\
\hline & -2.2 & KRTAP1-5 & keratin associated protein $1-5$ \\
\hline \multirow[t]{5}{*}{$*$} & -2.3 & HMGA2 & high mobility group AT-hook 2 \\
\hline & -2.3 & PAQR5 & progestin and adipoQ receptor family member $\mathrm{V}$ \\
\hline & -2.3 & MCM4 & minichromosome maintenance complex component 4 \\
\hline & -2.4 & CDC6 & cell division cycle 6 \\
\hline & -2.6 & SSTR1 & somatostatin receptor 1 \\
\hline
\end{tabular}


Table 4: Genes differentially expressed in hIMB cells $20 \mathrm{~h}$ after DUX4c-plasmid transfection

\begin{tabular}{lcll}
\hline & \multicolumn{3}{c}{ DUX4c 24 h } \\
\cline { 2 - 4 }$*$ & FC & Gene & \multicolumn{1}{c}{ Description } \\
\hline & 27.6067 & HPX-2 & homeobox HPX-2 \\
$*$ & 22.8739 & UBR4 & ubiquitin protein ligase E3 component n-recognin 4 \\
$*$ & 21.4539 & DUX3 & double homeobox 3 \\
$*$ & -2.0324 & KLF15 & Kruppel-like factor 15 \\
& -2.1708 & SLPI & secretory leukocyte peptidase inhibitor \\
& -2.2869 & IL18R1 & interleukin 18 receptor 1 \\
& -2.9995 & TRAF1 & TNF receptor-associated factor 1 \\
& -4.9447 & TNP2 & transition protein 2 (during histone to protamine replacement) \\
\hline
\end{tabular}

Asterisk labels genes that are also differentially expressed in DUX4-transfected IMBs.

Several functional categories including, transcription, angiogenesis, neuron development, cell signaling, cellular transport, protein degradation, and protein complex assembly that have not reach statistical significance in our study, were attributed to DUX4 target genes previously $[14,12,47]$. The validity of some of these functional categories has been experimentally proven: DUX4 overexpression in human myoblasts has been shown to induce genes involved in protein degradation [16] and interfere with protein ubiquitination
A

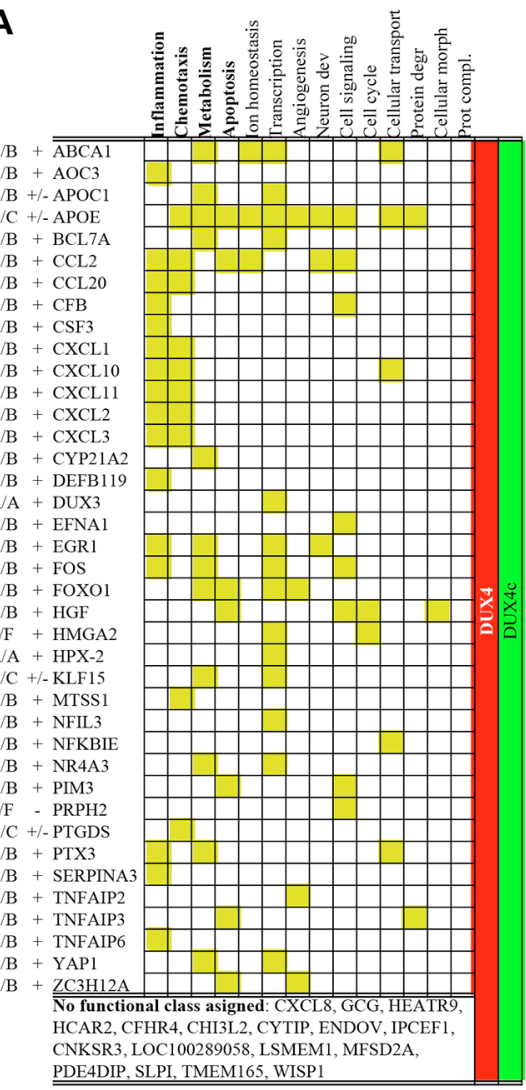

B

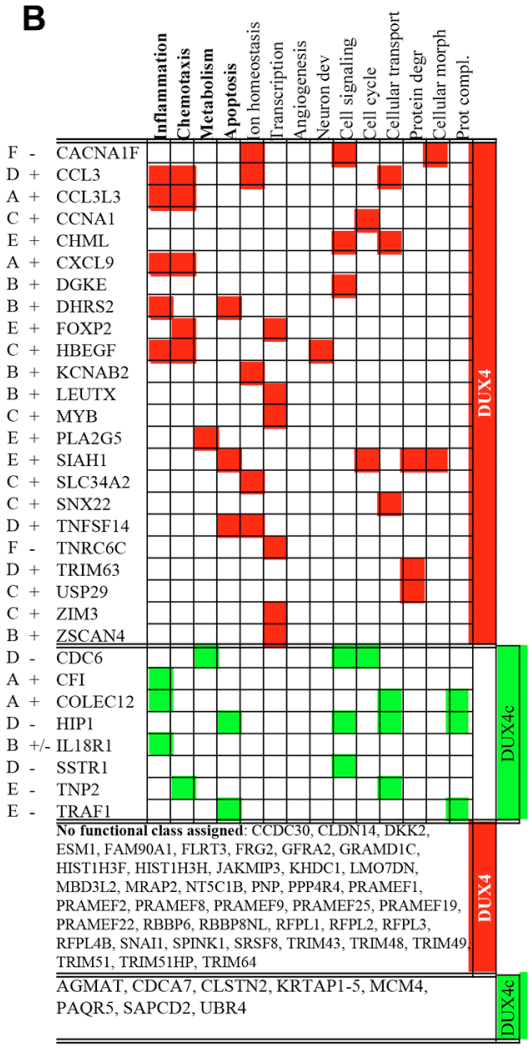

Figure 2: Functional classification of genes differentially expressed both in DUX4- and DUX4c- transfected human immortalized myoblasts (MB) (A) or only in DUX4- or DUX4c-transfected MB (B) at two time points (12- and $24 \mathrm{~h}$ ) after the transfection. Names of superclusters composed of several gene ontology functional categories (see supplementary Table S2 for the composition of superclusters) of which at least one was statistically significant $(p$-value $<0.05, \mathrm{FDR}<20)$ are in bold. Gene expression level at various time-points is indicated with letters (A-E or F) as in Figure 1; "+" and "-" indicate whether a gene was consistently up- or downregulated at all time points tested; "+/-" means that a gene was upregulated and one time-point but downregulated at the other. 
[48]. DUX4 overexpression in mouse embryonic stem cells (ES) has been shown to induce neuroectoderm program [49]; the involvement of DUX4 in transcription regulation has also been addressed [14]. Finally, DUX4 target genes found in this study also include FRG2 and KLF15 - genes shown previously to be overexpressed in FSHD; this is in agreement with an observation that DUX4 target genes are differentially expressed in FSHD [50].

As compared to $D U X 4 c, D U X 4$ overexpression resulted in a differential expression of more genes involved in chemotaxis, ion transport, and protein degradation. Conversely, all differentially expressed genes related to protein complex assembly were exclusively controlled by $D U X 4 c$ (Figure 2).

\section{$D U X 4$ overexpression results in upregulation of $C X C R 4$ and $S D F 1$ gene expression in various cell types}

DUX4 and DUX4c transcriptome signatures contained genes encoding chemokines. Of 18 chemokine genes reliably detected by the microarray (intensity $>50$ ) in $\mathrm{MB}, 10$ and 7 were at least 1.5 -fold upregulated in $D U X 4$ - and DUX4c-overexpressing MB, respectively (Figure 3A, 3B). A relatively weakly expressed $C X C R 4$ chemokine receptor gene was upregulated 2 to 5 -fold in DUX4- but not $D U X 4 c$-overexpressing $\mathrm{MB}$ as compared to the controls. Other chemokine receptor genes were either undetectable or not differentially expressed. qPCR and immunofluorescence microscopy analysis of CXCR4 expression in MB and mesenchymal stromal cells isolated from human bone marrow cells (BMSC) transfected with the DUX4 plasmid confirmed the results of transcriptome profiling (Figures 4, 5 and Supplementary Figure S3). Furthermore, we observed a significant upregulation of $C X C R 4$ expression in several other cell types transfected with $D U X 4$ including human keratinocyte cell line HaCat, dermal fibroblasts Dfb and mesenchymal stromal cells isolated from adipose tissue (ADAS) (data not shown).

CXCR4 receptor is activated by the interaction with its only known ligand SDF1. Our microarray analysis did not detect a differential expression of $S D F 1$ gene (Figure 3C, 3D); however, we observed a moderate but statistically significant upregulation of SDF1 mRNA and protein in DUX4- but not DUX4c-transfected MB (Figure 4A, 4B). DUX4-transfected myoblasts also secreted more SDF1 protein into extracellular medium (Figure 4D). SDF1 is also known to bind to a scavenger receptor CXCR7, however, no change in CXCR7 expression level was observed upon $D U X 4$ or $D U X 4 c$ overexpression (Figure 3C, 3D). It is also unlikely that $D U X 4$ expression is essential for CXCR4 or SDF1 expression as these genes are known to be expressed in various cells types, and DUX4 expression is confined to embryonic and germinal cells $[17,11]$.

\section{DUX4 overexpression stimulates migration of mesenchymal stem cells}

The efficiency of CXCR4 signaling depends on the expression level of both $S D F 1$ and $C X C R 4$ genes (reviewed in [41]). Our results thus suggested that DUX4 might regulate cell mobility and migration. To test the migration and chemoattractive properties of cells overexpressing $D U X 4$ and $D U X 4 c$, we used a Transwell assay. Migrating BMSC were plated on an upper layer of a permeable membrane placed in a Transwell insert and chemoattractantproducing human myoblasts were plated to the lower chamber section of the Transwell system (Figure $6 \mathrm{H}$ ). To test the effect of DUX4- and DUX4c overexpression on chemoattractive properties of $\mathrm{MB}$, we transfected them with DUX4 and DUX4c plasmids and counted the number of untransfected stromal cells derived from human bone marrow cells (BMSC) that crossed the membrane (Figure 6A). We observed a more efficient migration of BMSC towards DUX4- but not $D U X 4 c$ overexpressing MB. The effect was completely blocked if antibodies against SDF1 were added to the culture medium (Figure 6F). We have also tested whether DUX4 overexpression could increase chemoattractive properties of other cell types. We overexpressed $D U X 4$ in TE671 rhabdomyosarcoma cell line, known to be resistant to high levels of DUX4 expression $[13,51]$, human immortalized myoblasts (MB) and immortalized keratinocyte cells line HaCat and found that DUX4 overexpression also increases the chemoattractivity of these cells to BMSC (data not shown).

Next, we tested whether DUX4 or DUX4c overexpression could modify migration properties of BMSC, and observed an increase of migration rate of $D U X 4$ - but not $D U X 4 c$-trasfected BMSC towards untransfected MB (Figure 6B). This effect was further increased if $D U X 4$ but not $D U X 4 c$ was simultaneously overexpressed in both BMSC and MB (Figure 6C, 6D). Adding CXCR4 antibodies to the culture medium completely abolished the effect of DUX4 overexpression on cell migration (Figure 6G). Cell migration experiments have been carried out $24 \mathrm{~h}$ after the transfection as apoptosis and necrosis rate of the transfected cells at this time point was not significantly different from nontransfected controls (Supplementary Figure S1) arguing against the possibility that cytotoxic effect of DUX4 overexpression could introduce a bias in our assay.

To rule out the possibility that $D U X 4$ overexpression could affect BMSC and ADAS multipotency, we then induced adipogenic differentiation of DUX4-transfected BMSC. We found the number of resulting adipocytes unchanged as compared to a control plasmid-transfected BMSCs, thus arguing against the possibility that DUX4 altered adipogenic differentiation potential of BMSC and ADAS (Supplementary Figure S2).

We conclude that DUX4 but not DUX4c overexpression increases chemoattractivity of several cell 
A

A chemokine
mRNA expression fold change $\begin{array}{lllllllllllll}-4 & -3 & -2 & -1 & 0 & 1 & 2 & 3 & 4 & 5 & 6 & 7 & 8\end{array}$
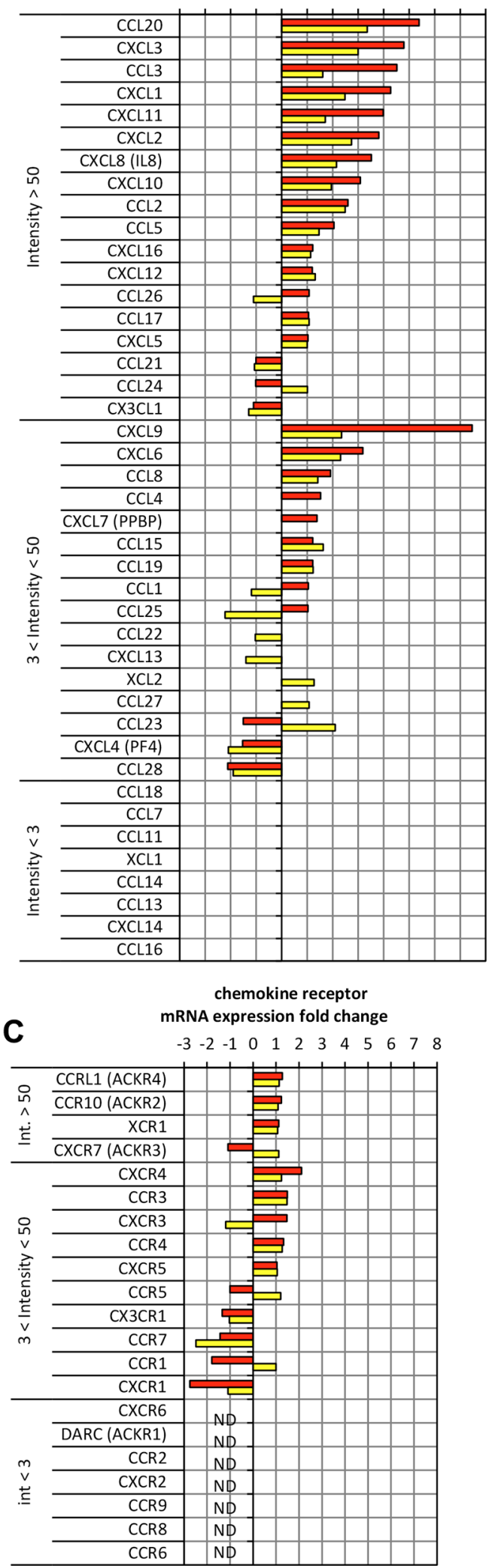

B expression fold change $\begin{array}{lllllllllllll}4 & -3 & -2 & -1 & 0 & 1 & 2 & 3 & 4 & 5 & 6 & 7 & 8\end{array}$

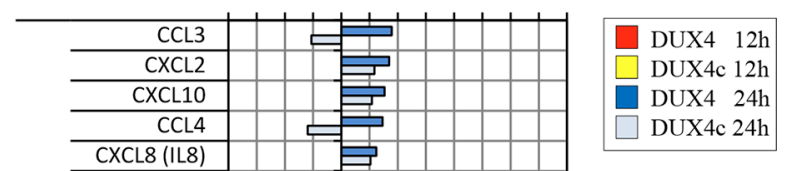

 CXCL3

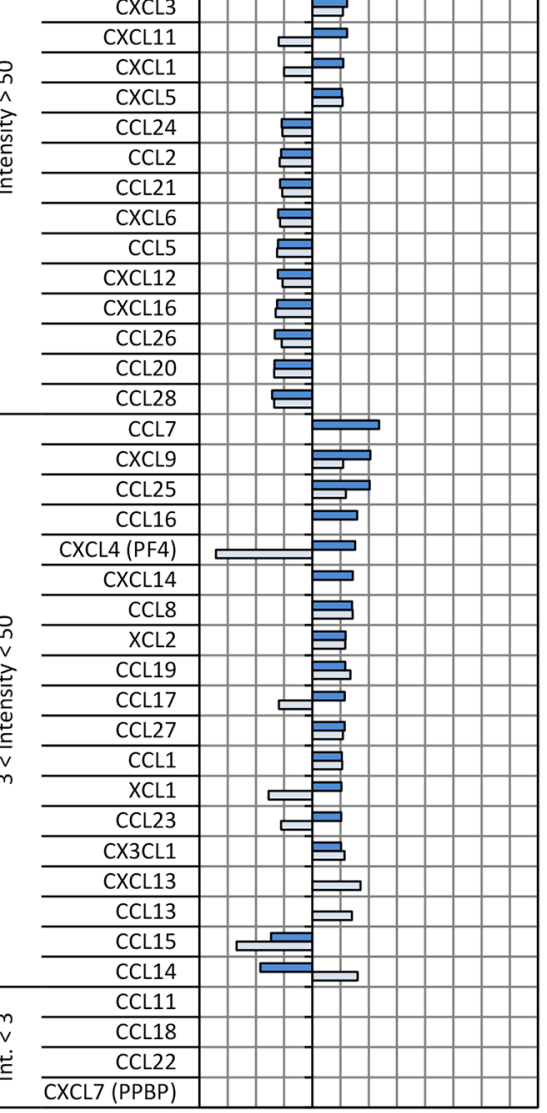

chemokine receptor mRNA expression fold change

D $\begin{array}{lllllllllllll}-4 & -3 & -2 & -1 & 0 & 1 & 2 & 3 & 4 & 5 & 6 & 7 & 8\end{array}$

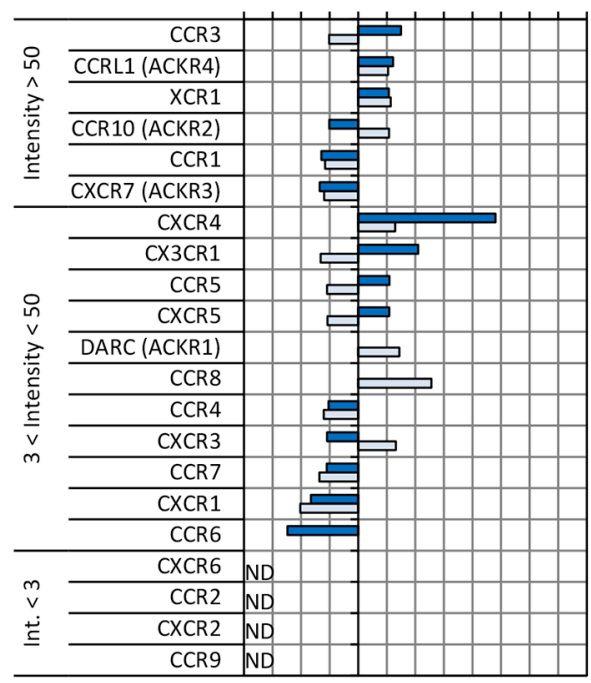

Figure 3: Chemokine (A, B) or chemokine receptor (C, D) gene mRNA expression (microarray) in human immortalized myoblasts (MB) 12 h or 24 h after transfection with DUX4 (A, C) or DUX4c (B, D) plasmids. Gene names are divided in 3 classes: highly expressed (int $>50)$, low expression $(3<$ int $<50)$ and non-detectable $($ in $<3)$ sorted according to fold change. 
types for MSC migration and also increased migration rate of BMSC when overexpressed in them. The difference in transcriptome signatures of DUX4 and DUX4coverexpressing myoblasts is thus clearly translated into different biological roles of these transcription factors.

\section{DISCUSSION}

\section{DUX4 and SDF1-CXCR4 axis in the normal organism}

DUX4 is a powerful transcriptional regulator with an unknown physiological role in normal cells. In vitro, full-length DUX4 is expressed in human embryonic and mesenchymal stem cells [17] and induced pluripotent stem cells [11]; its expression is downregulated in the process of differentiation of these cells. DUX4 expression cannot be detected in fully-differentiated cells such as primary myoblasts or fibroblasts where only DUX4-s, a shorter non-toxic form of DUX4 resulting from an alternative splicing of DUX4 gene could be detected.

In normal adult human tissues, full-length DUX4 is expressed only in testis; in somatic tissues including skeletal muscles, liver and heart only DUX4-s transcript was detectable [11]. The pattern of full-length DUX4 expression is indicative of a role at early stages of human development. However, besides the observation that DUX4 overexpression induced neuroectodermal program in murine embryonic stem cells, developmental functions of DUX4 remain unknown. Linking DUX4 with cellular migration described here may thus contribute to the understanding of a physiological role of DUX4 in development.

In the course of vertebrate development, SDF1 and CXCR4 are essential for colonization of the bone marrow by hematopoietic stem and progenitor cells (HSPCs) (reviewed in $[52,53,39,38]$ ), colonization of gonads by primordial germ cells (PGCs) [54] (reviewed in [38]); neurogenesis (reviewed in $[38,55]$ ); cardiogenesis and vascular formation [56]; limb myogenesis [57-61]. It is tempting to speculate that as an activator of CXCR4 and SDF1 expression, DUX4 might be also involved in these processes.

The role of DUX4 in development could, in principle, be addressed using loss of function mouse models. Mouse genome contains DUX4 homologs Duxbl
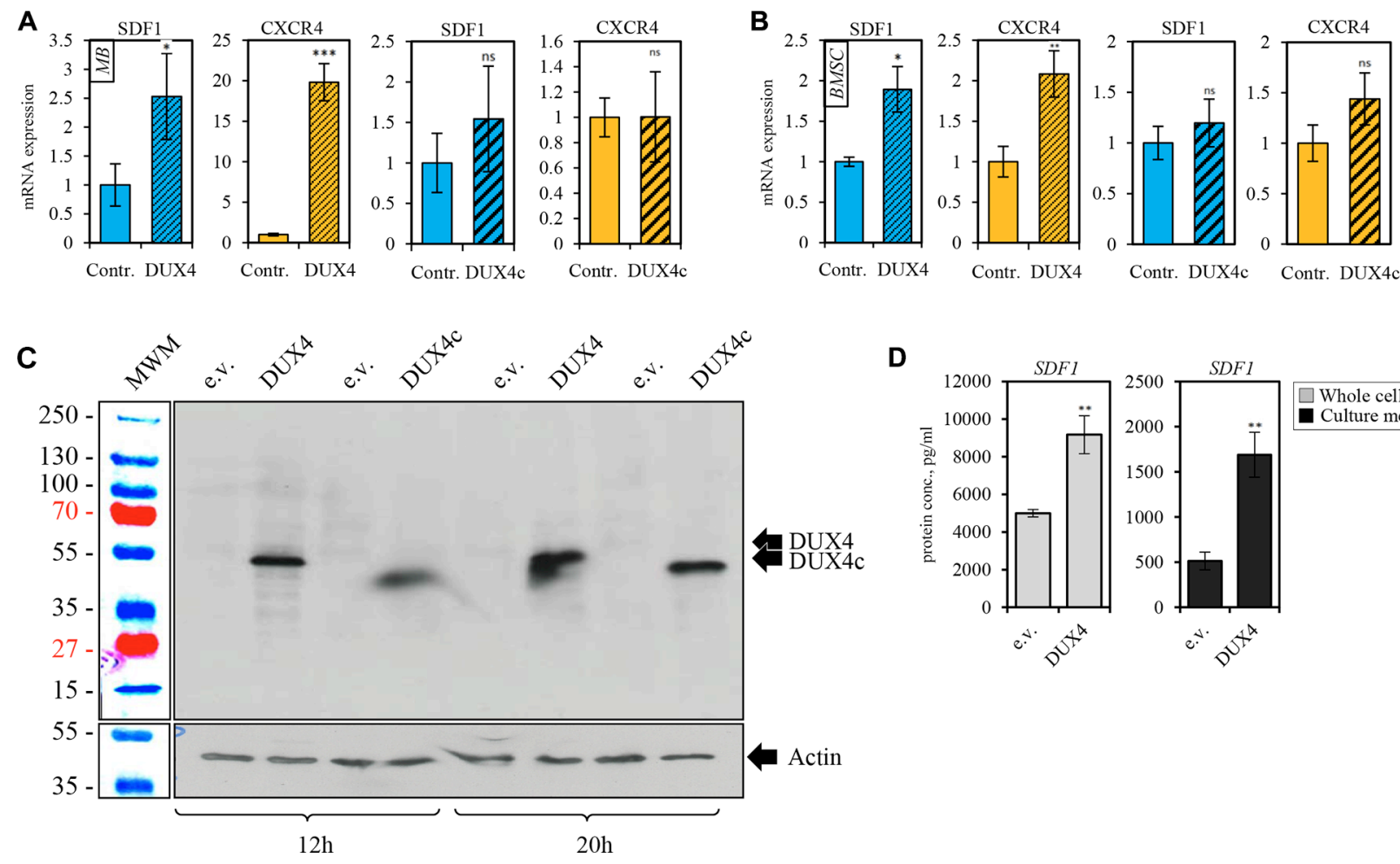

D

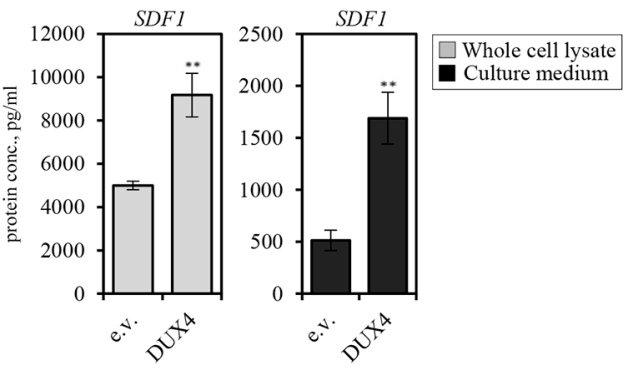

Figure 4: DUX4-transfected cells overexpress SDF1 and CXCR4 genes. qRT-PCR analysis of the expression of CXCR4 and SDF1 mRNA in human immortalized myoblasts (MB) (A) and bone marrow mesenchymal stem cells (BSMC) (B) transiently transfected with DUX4- or, DUX4c-expressing plasmids or an empty vector (pCI-Neo). Average of three independent experiments is shown, error bar represent standard deviation (SD), $t$-test $p$-value $<0.05\left(^{*}\right)$. Gene expression level of the control sample normalized to GAPDH was set to 1. (C) Western blot analysis of protein lysates of human immortalized myoblasts (MB) transfected with DUX4 and DUX4c plasmids for 12 and $20 \mathrm{~h}$. DUX4 (52-kDa) and DUX4c (47-kDa) proteins were stained with 9A12 antibody. (D) SDF1 protein concentration was measured using ELISA in the whole cell lysate (diluted 10-fold) or cell culture medium (concentrated 20 times) of human immortalized myoblasts (MB) $24 \mathrm{~h}$ after transfection with pCI-Neo-DUX4, or pCI-Neo (e.v.) plasmids. Average and standard deviation of 3 independent experiments are shown, $t$-test $p$-value $<0.05\left(^{*}\right)$. 
(also named Duxl) $[62,63]$ and Dux. The degree of amino acid identity of Duxbl and DUX4 reaches $65 \%$ in the most conserved region (second homeobox DNA binding domain) [62]. Expression pattern of Duxbl (ovary, eyes, testes and brain of adult mice and developing muscles of mouse embryos [64]) demonstrates a certain similarity to the DUX4 expression pattern. Functional analysis of Duxbl demonstrated that Duxbl overexpression increased myoblast proliferation but repressed their myogenic differentiation [65] which to certain extent recapitulated the effect of DUX4 overexpression on myogenic differentiation.

Another mouse homolog, Dux is only 60\% identical to DUX4 in its most conserved region; its expression pattern is also less similar to that of DUX4. Dux expression was demonstrated in adult mouse brain, heart liver and lungs and was almost undetectable in skeletal muscle [62]; functional analysis of this gene was not conducted. Duxbl or Dux loss-of-function mouse models are not yet available, and their relevance for understanding the physiological role is not clear.

\section{DUX4 and SDF1-CXCR4 axis in pathology}

While in normal adult organism the role of DUX4 is unknown and might be limited to germline, the role of DUX4 in pathology (i.e. in Facioscapulohumeral dystrophy or FSHD) has been extensively explored. In this disease, DUX4 expression could be detected in muscle cells and tissues [11] and is thought to contribute to the pathological phenotype by inducing apoptosis, provoking the sensitivity to oxidative stress and inhibiting myogenic differentiation. Inhibition of myogenic differentiation is one of the best understood functions of DUX4 in FSHD. Murine muscle satellite cells expressing human DUX4 are unable to properly differentiate in vitro [21] or regenerate skeletal muscle tissue in vivo [66].

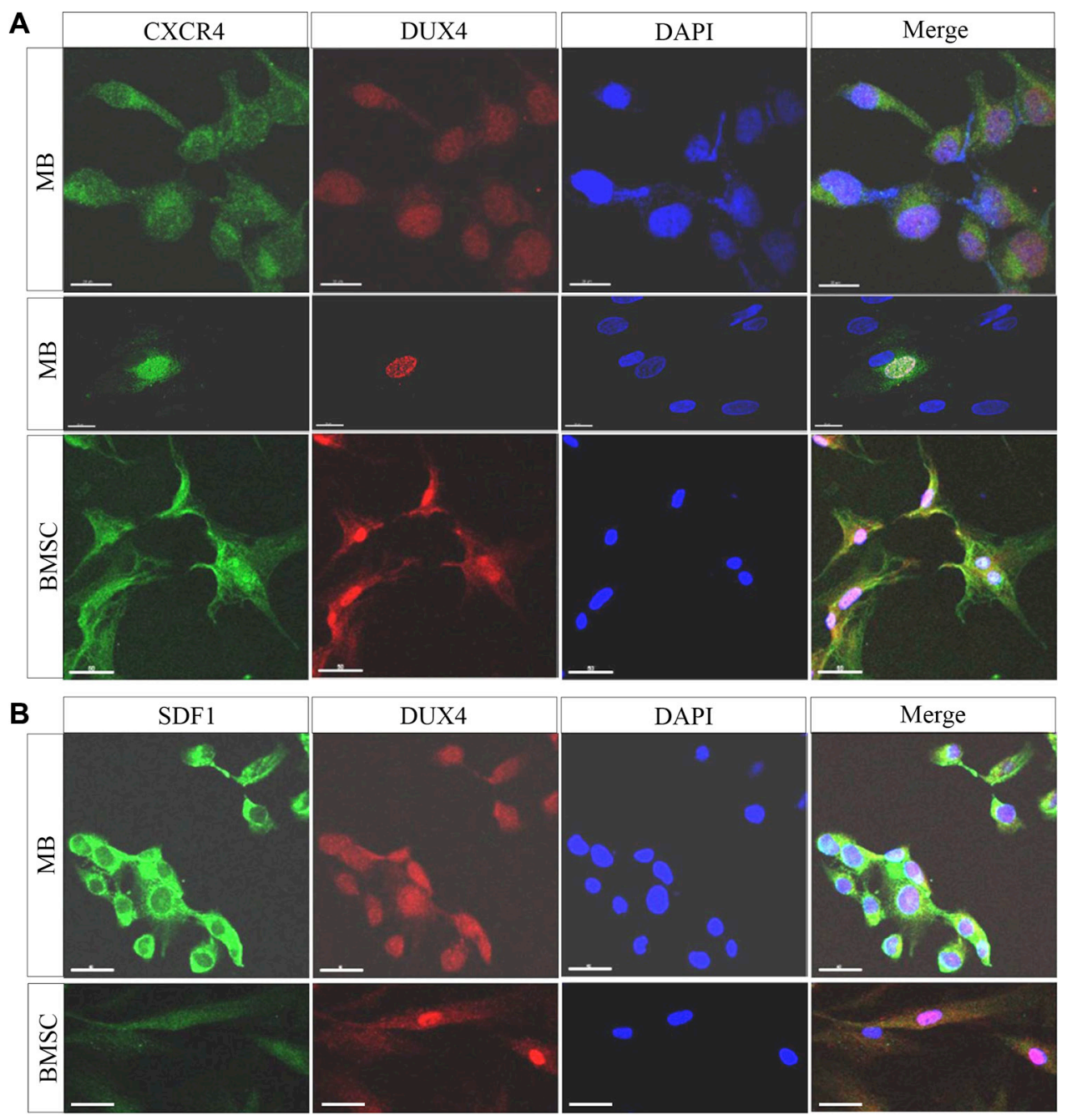

Figure 5: DUX4-transfected cells overexpress SDF1 and CXCR4. Immunofluorescence analysis of CXCR4 and DUX4 expression in human immortalized myoblasts (MB) (A) and bone marrow-derived mesenchymal stromal cells (BMSCs) (B) $24 \mathrm{~h}$ after the transfection with pCI-NeoDUX4 plasmid. Formaldehyde-fixed cells were stained with CXCR4, SDF1 and DUX4 antibodies, representative images are shown; scale bar $50 \mu \mathrm{m}$. 
Inhibition of the myogenic program by DUX4 could be explained by a similarity of recognition sites of DUX4 and Pax3/7 transcription factors essential for the commitment of myogenic progenitors resulting in an interference with the early myogenic differentiation steps [14]. It has also been demonstrated that DUX4 induced the expression of muscular atrophy-related genes $[67,16]$ myogenic microRNAs [68] and transcription factors [14, 47] suggesting that DUX4 might also interfere with later stages of myogenic differentiation.

Interestingly, CXCR4 is also involved in the regulation of myogenic differentiation. CXCR4 is expressed on the surface of both proliferating and differentiated $\mathrm{C} 2 \mathrm{C} 12$ cells $[58,61,69]$. SDF1 expression is increased while CXCR4 decreased during myogenic differentiation of rat myoblasts [70]; however, the role of CXCR4-SDF1 axis in myogenic differentiation remains controversial. Some reports have shown inhibition of myogenic differentiation by SDF1 of CXCR4 signaling [69] or no effect [70]. Other reports have shown that SDF1 induced myotube formation while CXCR4 inhibition via siRNA blocked $\mathrm{C} 2 \mathrm{C} 12$ differentiation [71]. The mechanism of CXCR4-dependent regulation of myogenic differentiation is thought to involve MAPK signaling. Intriguingly, MAPK signaling-related genes were identified in DUX4 transcriptomic signature [47]. CXCR4 as one of DUX4 target genes might thus also contribute to FSHD etiology.
Besides an abnormal myogenic differentiation, an accumulation of leukocytes has been also documented in FSHD muscles [72]; the mechanism of this phenomenon is currently unknown. It has been demonstrated that CXCR4 receptor plays a key role in chronic inflammatory conditions such as inflammatory bowel disease (reviewed in [73]), chronic allergic lung inflammation, idiopathic pulmonary fibrosis, liver fibrosis [74], rheumatoid arthritis (reviewed in [75]).

Our results allow us to put forward a hypothesis that DUX4 overexpression resulting in SDF1 expression in FSHD muscles might result in an increased migration of leukocytes to FSHD muscles. It is plausible therefore that DUX4 might be involved in these processes as its aberrant expression in FSHD muscles might activate SDF1 and thus attract circulating CXCR4+ leukocytes which would result in their infiltration to FSHD muscles. Again, this possibility could, in principle, be tested using mouse models of ectopic expression of human DUX4 that have recently been described. Mice expressing human DUX4 under the control of its natural promoter did not show visible phenotypic anomalies except for the eye keratitis of unknown etiology [21]. At the same time, mice expressing DUX4 under the control of a leaky doxycycline-inducible promoter in retina, testis, skin, brain, kidney, and lung, had scaly skin, muscle weakening, increased retina neovascularization, males demonstrated a defect in gametogenesis [66]. Although the latter mouse
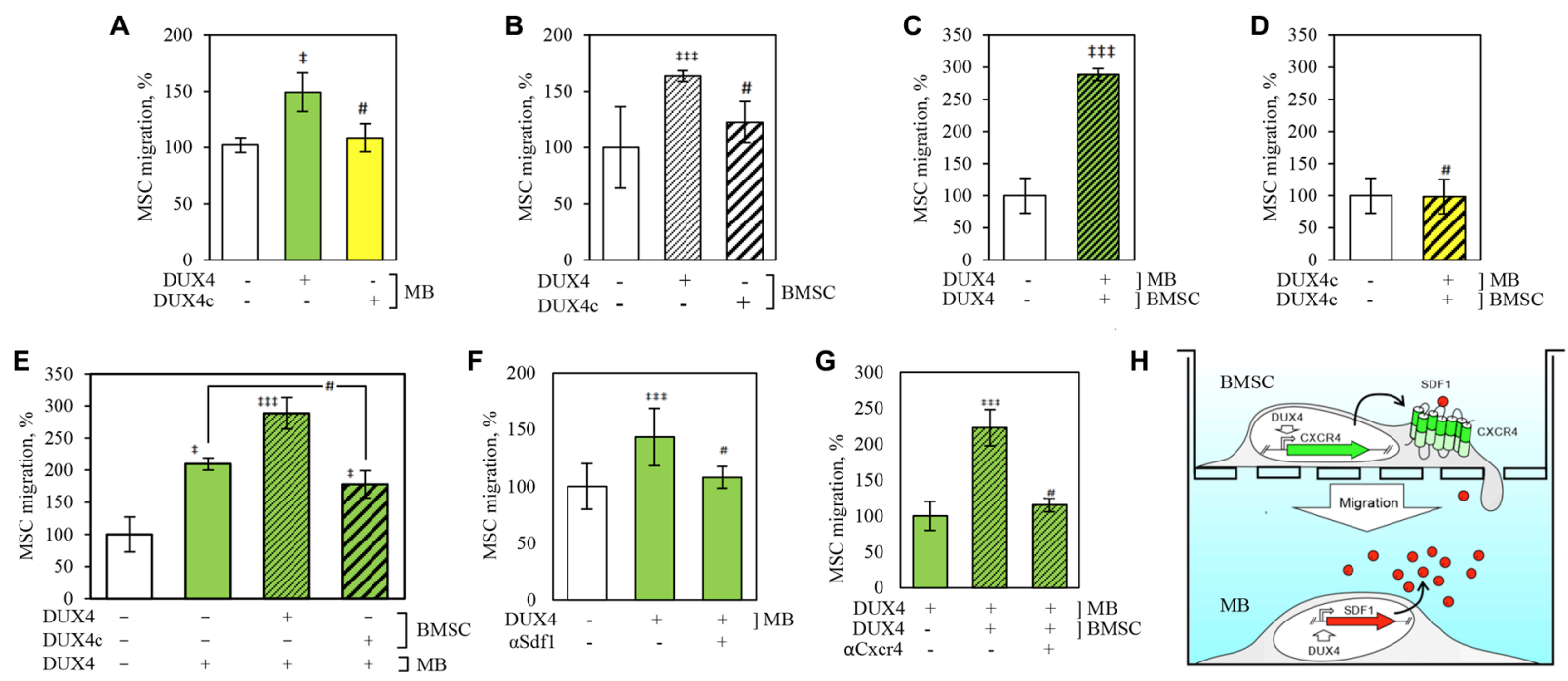

Figure 6: DUX4 and DUX4c expression increases migration rate of human bone marrow stem cells (BMSC) towards human immortalized myoblasts (MB) in a transwell assay. BMSC and MB cells were plated to the upper- and the lower wells of a Transwell chamber respectively and the number of BMSC that crossed the membrane and adhered to its lower surface was quantified. (A) Migration of non-transfected BMSCs towards MB transfected with DUX4-, DUX4c-plasmid or an empty-vector control (e.v.); (B) Migration of BMSCs transfected with DUX4-, DUX4c-plasmid or e.v. towards non-transfected MB; (C) Migration of BMSCs transfected with DUX4- or e.v. towards DUX4- or e.v.-transfected MB; (D) Migration of BMSCs transfected with DUX4c- or e.v. towards DUX4c- or e.v.-transfected MB; (E) Migration of BMSCs transfected with DUX4-, DUX4c- or e.v. towards DUX4- or e.v.-transfected MB; (F) Effect of SDF1 antibody on BMSC migration towards MB transfected with DUX4-plasmid or e.v. (G) Effect of CXCR4 antibody on migration of BMSC transfected with DUX4-plasmid or e.v. towards DUX4-plasmid or e.v.-transfected MB; (H) Schematic representation of DUX4 overexpression impact on BMSC cell migration towards MB. $(*), p$-value $<0.05$ as compared to control; \#, non-significant; migration to e.v.-transfected cells was set to $100 \%$, error bars correspond to SD. 
model had some phenotypical features common to FSHD, its relevance as a model of FSHD is thus unclear.

\section{DUX4 in cancer}

Finally, DUX4 is also known to be expressed in many cancer cell lines including rhabdomyosarcoma RD (CCL-136) and RMS13 (CRL-2061) [13, 76], cervix carcinoma HeLa, lung adenocarcinoma A549 cell lines [76] and in non-small cell lung cancer (NSCLC) cells [76]; DUX4 or a homologous transcript was detected in cervical carcinoma cell line C33A [77]. Recurrent DUX4 fusions have been detected in B cell acute lymphoblastic anemia [78], embryonal rhabdomyosarcoma [79], Ewing-like sarcomas [80] and pediatric primitive round cell sarcomas [81]. The mechanism of DUX4 upregulation in cancer cells remains unknown, although it has been proposed that it is linked to demethylation of the $3.3 \mathrm{~kb}$ repeats harboring DUX4 ORF [82, 77, 83].

Tumor cells are known to secrete SDF, inflammatory cytokines and growth factors which together promote MSC homing to the tumor site [84]. MSC infiltration has been proven beneficial for some tumor types [85]. One possibility that is suggested by our results but has not been tested in this study is that DUX4 might contribute to the MSC infiltration into tumors. Another possibility that was not addressed in the present study is that DUX4 expression might influence metastatic potential of cancer cells via CXCR4-SDF1 axis. SDF1-CXCR4 signaling is also involved in migration of cancer cells to the sites of metastasis (SDF1-expressing tissues, such as bone marrow and lung) including breast, lung, ovarian, thyroid, rhabdomyosarcoma and others (over 20 human tumor types (reviewed in [86]) [53, 87, 86-89]. Our study thus prompts to test whether DUX4 overexpressing tumors demonstrate an increased metastatic potential as compared to DUX4-negative tumors.

\section{MATERIALS AND METHODS}

\section{Cell culture conditions, plasmids and transfection}

Human immortalized myoblasts (MB) generated from a healthy subject (a kind gift of Dr. V. Mouly, Institute of Myology, Paris) were cultured in the media composed of 4 parts of high-glucose DMEM, 1 part of Medium 199 (Sigma \#M4530) and supplemented with $20 \%$ FBS $4 \mathrm{mM}$ L-glutamine $50 \mathrm{mkg} / \mathrm{ml}$ gentamicin, $1 \mathrm{mkg} / \mathrm{ml}$ Amphotericin B, $2.5 \mathrm{ng} / \mathrm{ml}$ human recombinant HGF (Sigma \#H1404) and $1 \mathrm{mkM}$ dexamethasone (Sigma \#D4902) as described previously [90].

Human primary myoblasts were isolated from skeletal muscle biopsies of healthy subjects and purified using CD56/NCAM magnetic beads (Miltenyi Biotec) as previously described [91], preserved in liquid nitrogen and transported for future use. After unfreezing, the myoblasts were cultured in proliferation medium (high-glucose DMEM (here and below \#D6546, Sigma), 20\% FBS FBS (Millerium \#BWSTS1810/500), 4 mM L-glutamine (Sigma \#68540-25 G), 50 g/ml gentamicin (G1397 Sigma), 1 $\mathrm{mkg} / \mathrm{ml}$ Amphotericin B (Fungizone, Gibco \#15290-018)), passaged at a cell confluence not exceeding $30 \%$ and used for transfection and tests up to passage 5 or earlier to avoid cellular senescence and spontaneous differentiation.

Both primary and immortalized myoblasts were cultured in cell culture dishes coated with collagen using sterile $0.1 \%$ solution of collagen powder (\#C7661 Sigma) in $0.2 \%$ acetic acid.

Human bone marrow-derived mesenchymal cells (BMSC) were isolated as previously described [92]. Briefly, mononuclear cells were isolated from bone marrow aspirates from healthy donors using centrifugation in Histopaque-1077 density gradient (Sigma) at $400 \mathrm{~g}$ for 30 min at room temperature; the resulting cells were washed 3 times with DMEM, plated at $10^{\wedge} 6$ cells $/ \mathrm{cm} 2$ in cell culture flasks (Greiner Bio-One) and cultured the growth medium (low-glucose DMEM (Gibco) supplemented with 10\% fetal bovine serum (FBS) (HyClone), 2 mM GlutaMAX ${ }^{\mathrm{TM}}$ (Gibco), and $50 \mathrm{U} / \mathrm{ml}$ of penicillin and $50 \mathrm{ug} / \mathrm{ml}$ of streptomycin (Gibco); medium was changed every 3 days.

Human adult adipose tissue-derived stem cells (ADAS) were isolated as previously described [92]. Briefly, the adipose tissue aspirates was washed with phosphate-buffered saline (PBS), containing $50 \mathrm{U} / \mathrm{ml}$ of penicillin and $50 \mathrm{ug} / \mathrm{ml}$ of streptomycin (Gibco), then digested at $37^{\circ} \mathrm{C}$ for 60 min with $0.075 \%$ collagenase type I (Worthington). The cell suspension was washed with DMEM, containing 10\% FBS and centrifuged at $300 \mathrm{~g}$ for $10 \mathrm{~min}$. The pellet was resuspended in $160 \mathrm{mM} \mathrm{NH} 4 \mathrm{Cl}$ and incubated at room temperature for $10 \mathrm{~min}$ to lyse contaminating red blood cells. The cell suspension was centrifuged as detailed above, the pellet was resuspended in DMEM supplemented with $20 \%$ FCS filtered through a 100-um nylon mesh to remove cellular debris, plated at culture flasks and incubated overnight at $37^{\circ} \mathrm{C}, 5 \%$ $\mathrm{CO} 2$. Following incubation, the flasks were washed extensively with PBS to remove residual nonadherent blood cells. ADAS were cultured in growth medium DMEM/F12 (Gibco), supplemented with 10\% FBS, 2 $\mathrm{mM}$ GlutaMAX ${ }^{\mathrm{TM}}, 50 \mathrm{U} / \mathrm{ml}$ of penicillin and $50 \mathrm{ug} / \mathrm{ml}$ of streptomycin (Gibco). The medium was changed every 3 days, cells were maintained at subconfluent levels.

TE-671 and HaCat cell lines were cultured in DMEM medium supplemented with $4.5 \mathrm{~g} / \mathrm{L}$ glucose (Gibco), $2 \mathrm{mM}$ L-glutamine, 10\% fetal bovine serum and $100 \mathrm{u} / \mathrm{ml}$ penicillin and $100 \mathrm{ug} / \mathrm{ml}$ of streptomycin.

\section{Adipogenic differentiation}

ADAS and BMSC were plated in 12-well plates at a density of $5 \times 10^{3}$ cells $\mathrm{cm}^{-2}$ and transfected with 
DUX4-, DUX4c- or control vector when indicated. After $24 \mathrm{~h}$ the growth media was replaced with adipogenic induction medium: DMEM, 10\% FBS, $0.5 \mathrm{mM}$ isobutylmethylxantine (Sigma), 1 uM dexamethasone (Sigma), $10 \mathrm{uM}$ insulin (Sigma), $0.2 \mathrm{mM}$ indomethacin (Sigma); the medium was changed every three days. After 21 days cells were fixed with $4 \%$ paraformaldehyde in PBS and lipid droplets were revealed by histochemical staining with Oil Red O dye (Sigma) for neutral fats. For quantification, Oil Red O stain was extracted with $100 \%$ isopropanol for $5 \mathrm{~min}$, absorbance was measured at $492 \mathrm{~nm}$ and normalized to the number of cells; $100 \%$ isopropanol was used as a background control; the experiments were performed in quadruplicates.

Transfection. $8 \times 10^{4}$ of human MB cells were resuspended in $400 \mathrm{mkl}$ of corresponding culturing medium, mixed with $80 \mathrm{mkl}$ of OptiMEM (Gibco \#31985062) containing $240 \mathrm{ng}$ of plasmid DNA and 0.24 mkl Lipofectamine 2000 (Invitrogen, \#11668-019) and plated into 1 well of a 12 -well plate $\left(2.1 \times 10^{4}\right.$ cells/ $\mathrm{cm} 2$ ); medium was changed $6 \mathrm{~h}$ after the transfection. The transfection efficiency was around $40 \% .2 \times 10^{4}$ BMSC or ADAS cells were plated in a well of a12-well plate $(5 \times$ $10^{3}$ cells $\left./ \mathrm{cm} 2\right)$ and transfected using $1 \mu \mathrm{g}$ of plasmid DNA and $1 \mathrm{mkl}$ of Lipofectamine $2000^{\mathrm{TM}}$ (Invitrogen) according to the supplier's instructions; medium was changed $6 \mathrm{~h}$ after the transfection. The transfection efficiency was 80-90\%.

To overexpress DUX4 and DUX4c, we used pCINeo-DUX4 [3] and pCI-Neo-DUX4c [22] plasmids containing human DUX4 and DUX4c ORFs genes under control of the CMV promoter (a kind gift of Alexandra Belayew and Frederique Coppée, University of Mons, Belgium); Following control plasmids were used: pCI-Neo (Promega), phrGFP (Stratagene) and pCI-Neo-DUX1 [2].

\section{Immunofluorescence staining}

$24 \mathrm{~h}$ after the transfection MB or BMSC cells were fixed with 2\% PFA (Euromedex) in PBS for $5 \mathrm{~min}$, permeabilized with $0.5 \%$ triton X-100 (Sigma-Aldrich) in PBS for $5 \mathrm{~min}$, blocked with 5\% BSA (Euromedex) in PBS for $1 \mathrm{~h}$, incubated with mouse monoclonal antibodies against DUX4 clone 9A12 [67] (kindly donated by Alexandra Belayew, University of Mons, Belgium) diluted 1:50; rabbit polyclonal antibody against CXCR4 (Abcam \#ab 2074) diluted 1:100 or rabbit polyclonal antibody against SDF1 (CXCL12) (Abcam \#ab 9797) diluted 1:200 in $2.5 \%$ PBS in BSA, stained with Alexa Fluor 488-conjugated anti-rabbit IgG (Life Technologies \#A$21441,1: 100)$ for $2 \mathrm{~h}$ or Alexa Fluor 488 anti-mouse IgG (Life Technologies \#A-21200, 1:100) for 1 h 2.5\% PBS in BSA and mounted with a mounting medium containing DAPI (Vector laboratories), observed under a fluorescent microscope (Microvision instruments, excitation/emission: 488/519 nm, green fluorescence);

\section{Western blot}

Whole cell protein extracts were prepared from frozen immortalized or primary myoblast cell pellets using TENT buffer (150 mM NaCl, $1 \mathrm{mM}$ EDTA, $50 \mathrm{mM}$ Tris- $\mathrm{HCl} \mathrm{pH} 7.5,0.5 \%$ NP-40) [93] supplemented with anti-protease and anti-phosphatase inhibitor cocktails (\#04693159001, \#04906845001, Roche), separated on $8 \%$ PAAG, transferred to a nitrocellulose membrane (Amersham), blocked with 5\% milk/PyTBST, hybridized with primary antibodies 9A12 [67] recognizing DUX4 and DUX4c diluted 1:2000, washed with $1 \times$ PyTBST $(10 \mathrm{mM}$ Tris- $\mathrm{HCl}$ pH7.4, 75 mM NaCl, 1 mM EDTA, 0.1\% Tween 20) [94] to reduce background, hybridized with secondary antibodies conjugated to HRP (SantaCruz \#sc2030, \#sc2768, \#sc2005) diluted 1.2000, revealed with ECL+ (GE Healthcare), exposed to X-ray film (Amersham) and developed in a chemical film processor (FujiFilm). Quantification of scanned X-ray images was performed using ImageJ. After exposition the membranes were stripped in a solution containing $2 \%$ SDS and $100 \mathrm{mM}$ beta-mercaptoethanol buffered with $62.5 \mathrm{mM}$ TrisHCl, reblocked in 5\% BSA/PBS overnight and rehybridized with mouse monoclonal antibodies against actin (Millipore \#mab1501) diluted 1:10 000.

Flow cytometry apoptosis assay was performed using a CFTM488A Annexin V and 7-AAD Apoptosis Kit (Biotium, cat \# 30060). 24 or $72 \mathrm{~h}$ after transfection, MB or BMSC cells were trypsinized, centrifuged, resuspended in PBS. To avoid the loss dead cells, the media with detached cells was also collected and centrifuged at $300 \mathrm{~g}$ for $5 \mathrm{~min}$, the cells pellet was resuspended in PBS. The cells were stained according manufacture protocol. Briefly, cells were resuspended at $5 \times 10^{6}$ cells $/ \mathrm{ml}$ in $1 \mathrm{X}$ Annexin Binding Buffer, 5 ul of Annexin $\mathrm{V}$ and 2 ul of 7-AAD working solutions were added into the cell suspension and incubated at $4^{\circ} \mathrm{C}$ for $30 \mathrm{~min}$ in a dark. Then $400 \mathrm{ul}$ of $1 \mathrm{X}$ Annexin Binding Buffer was added and probes were analyzed by flow cytometry on the Cell Lab Quanta SC (Beckman Coulter, Brea, CA, USA)

\section{Transcriptome profiling}

RNA from human MB cells 12- and $20 \mathrm{~h}$ after the transfection with pCI-Neo-DUX4, pCI-Neo-DUX4c or pCI-Neo plasmids was extracted using Trizol (Invitrogen) as instructed by the producer and further purified with silica column cleanup using Nucleospin RNA Extraction kit (Macherey Nagel). $500 \mathrm{ng}$ of RNA were used to synthesize Cy3- (control) and Cy5- (DUX4- and DUX4ctransfected MB) labeled probes in a two-step procedure using Agilent Fluorescent Low Input Linear Amplification kit. Mix. Labeled probes were then hybridized to Gene Expression microarrays $(4 \times 44 \mathrm{k} \# \mathrm{G} 4112 \mathrm{~F}$, Agilent) and scanned using Agilent G2505C DNA Microarray scanner as instructed by the manufacturer. Scanned 
images were then analysed using the Feature Extraction software (Agilent, version 10.5.1.1) and gene expression fold change was calculated using Rosetta Resolver (version 7.2.2.0). In the case of DUX4-transfected cells, genes with $\mathrm{FC}<-3$ and Int $1(\mathrm{Cy} 3)>50$ were considered downregulated; genes with $\mathrm{FC}>3$ and Int2 (Cy5) $>50$ were considered upregulated; in the case of DUX4ctransfected cells, genes with $\mathrm{FC}<-2$ and Int1 (Cy3) $>$ 50 were considered downregulated; genes with $\mathrm{FC}>2$ and Int2 $($ Cy5 $)>50$ were considered upregulated. Gene symbols and descriptions corresponding to significant Agilent IDs were retrieved from the Agilent microarray annotation file and $\mathrm{db} 2 \mathrm{db}$ and DAVID gene ID conversion tools. In case of disagreement between the sources, HGNC database (http://www.genenames.org/) was consulted. Probes corresponding to non-annotated genes were not analyzed. Protein-coding genes differentially expressed in DUX4 and DUX4c transfected MB were used for functional annotation with DAVID (http://david.abcc. ncifcrf.gov/) using GOTERM_BP_FAT list and the default background. The stringency of functional annotation clustering was set to "medium". Clusters with similar biological functions containing at least one significant GO term (acceptable significance: $p$-value $<0.05$, FDR $<$ 20) were manually combined using Microsoft Excel with Ablebits add-ons "Cell merge" (https://www.ablebits. com/) resulting is superclusters "Cell cycle", "Apoptosis" etc.; The significance of a supercluster was considered to be equal to $p$-value and FDR corresponding to the most significant GO term within this supercluster.

\section{RT-PCR}

Total RNA was extracted using Trizol (Invitrogen) as instructed by the producer; the traces of phenol and salts were eliminated with 2 supplementary chlorophorm extractions, ethanol precipitation and two additional washes with $70 \%$ ethanol. $100 \mathrm{ng}$ of purified RNA was then reverse transcribed using Revertaid $\mathrm{H}$ minus Reverse transcriptase (Fermentas \#EP0451) as instructed by the producer, random hexamers and other RT components were also from Fermentas. cDNA was then diluted 10 times and $2 \mathrm{mkl}$ was mixed with primers (300 $\mathrm{nM}$ final) FastStart Universal SYBR Green Master mix (ROX) (Roche \#04913850001) in a final volume of $20 \mathrm{mkl}$ and analyzed on Step One plus instrument (Applied Biosystems). The sequence of primers (Invitrogen) used: SDF1-F2 5'-GAACGCCAAGGTCGTGGTCGT; SDF1-R2 5'-TCTGTAGCTCAGGCTGACGGGC; CXCR4-F1 5'-A AAGTACCAGTTTGCCACGGC; CXCR4-R1 5'-GCATG ACGGACAAGTACAGGCT; GAPDH-F2 5'-TCATTTC CTGGTATGACAACGA; GAPDH-R2 5'-TACATGGCA ACTGTGAGGAG; Reactions were performed in triplicates, DDct method was used to analyze data [95].

\section{Migration assays}

Migration assays were carried out in a 24well transwell system equipped with porous $(8 \mu \mathrm{m})$ polycarbonate membranes. $2 \times 10^{5} \mathrm{MB}$ cells were resuspended in $600 \mu \mathrm{L}$ of growth medium supplemented with $1 \% \mathrm{FBS}$ and plated into the lower chamber of the transwell system; $5.0 \times 10^{4} \mathrm{BMSC}$ cells were resuspended in $200 \mathrm{mkl}$ of growth medium supplemented with 1\% FBS and plated into Transwell inserts which were then placed into another transwell system with the lower chamber filled with $600 \mu \mathrm{l}$ of serum-free medium. After 24 hours the cells on the inserts or in lower chambers were transfected as indicated, 6 hours after the transfection the media was changed and the inserts with BMSC, were placed into the wells with MB cells and incubated at $37{ }^{\circ} \mathrm{C}$ for $24 \mathrm{~h}$. When indicated, CXCR4 (Abcam, \#ab10403) or SDF1 (CXCL12) (Abcam, \#ab9797) antibodies were added to the medium at $10 \mathrm{mkg} / \mathrm{ml}$ and $4 \mathrm{mkg} / \mathrm{ml}$ concentrations respectively. The inserts were then discarded, and upper sides of the filters were swabbed to remove the cells that did not cross the membrane. The cells present on the lower side of the filters were then fixed in $4 \%$ paraformaldehyde, stained with DAPI and the counted under the microscope. All the experiments were performed in duplicate. The following control antibodies were used: rabbit IgG control (AB-105-C, R\&D systems) and mouse IgG2b isotype control (MAB004, R\&D systems).

\section{SDF-1 $\alpha$ ELISA assay}

$3 \times 10^{6} \mathrm{MB}$ cells were plated on $10 \mathrm{~cm}$ dish and after $24 \mathrm{~h}$ were transfected with $8 \mu \mathrm{g}$ of plasmid DNA using JetPEI as instructed by the producer (Polyplus transfection), ratio plasmid:JetPEI was 1:2; medium was changed $24 \mathrm{~h}$ after the transfection. To quantify secreted CXCL12, the medium was collected $48 \mathrm{~h}$ after the transfection, centrifuged at $10000 \mathrm{rpm}$ for $10 \mathrm{~min}$ and concentrated 20 times using a $15 \mathrm{ml}$ spin concentrators (5 KDa MWCO) (Agilent Technologies). To quantify intracellular CXCL12, whole cell lysates were prepared in $500 \mu \mathrm{l}$ of RIPA buffer and diluted 10 times prior to analysis. Samples were analyzed in triplicates using human SDF $1 \alpha$ ELISA Kit (Abcam \#ab100637).

\section{ACKNOWLEDGMENTS}

The research has been supported by the MEGAFSHD grant from the Association Française contre les Myopathies (AFM) to YSV. PD was supported by Association de Recherche Contre le Cancer (ARC), and the Amis FSH association. The work of EK was partly conducted in the frame of the IDB RAS government program of basic research № 0108-2014-0004. 


\section{CONFLICTS OF INTEREST}

None.

\section{REFERENCES}

1. Zhong YF, Holland PW. The dynamics of vertebrate homeobox gene evolution: gain and loss of genes in mouse and human lineages. BMC Evol Biol. 2011; 11:169.

2. Ding H, Beckers MC, Plaisance S, Marynen P, Collen D, Belayew A. Characterization of a double homeodomain protein (DUX1) encoded by a cDNA homologous to 3.3 kb dispersed repeated elements. Hum Mol Genet. 1998; 7:1681-1694.

3. Gabriels J, Beckers MC, Ding H, De Vriese A, Plaisance S, van der Maarel SM, Padberg GW, Frants RR, Hewitt JE, Collen D, Belayew A. Nucleotide sequence of the partially deleted D4Z4 locus in a patient with FSHD identifies a putative gene within each $3.3 \mathrm{~kb}$ element. Gene. 1999; 236:25-32.

4. Beckers M, Gabriels J, van der Maarel S, De Vriese A, Frants RR, Collen D, Belayew A. Active genes in junk DNA? Characterization of DUX genes embedded within $3.3 \mathrm{~kb}$ repeated elements. Gene. 2001; 264:51-57.

5. Booth HA, Holland PW. Annotation, nomenclature and evolution of four novel homeobox genes expressed in the human germ line. Gene. 2007; 387:7-14.

6. Holland PW, Booth HA, Bruford EA. Classification and nomenclature of all human homeobox genes. BMC Biol. $2007 ; 5: 47$.

7. Hewitt JE. Loss of epigenetic silencing of the DUX4 transcription factor gene in facioscapulohumeral muscular dystrophy. Hum Mol Genet. 2015.

8. Hewitt JE, Lyle R, Clark LN, Valleley EM, Wright TJ, Wijmenga C, van Deutekom JC, Francis F, Sharpe PT, Hofker M. Analysis of the tandem repeat locus D4Z4 associated with facioscapulohumeral muscular dystrophy. Hum Mol Genet. 1994; 3:1287-1295.

9. Alkan C, Kidd JM, Marques-Bonet T, Aksay G, Antonacci F, Hormozdiari F, Kitzman JO, Baker C, Malig M, Mutlu O, Sahinalp SC, Gibbs RA, Eichler EE. Personalized copy number and segmental duplication maps using next-generation sequencing. Nat Genet. 2009; 41:1061-1067.

10. Wright TJ, Wijmenga C, Clark LN, Frants RR, Williamson R, Hewitt JE. Fine mapping of the FSHD gene region orientates the rearranged fragment detected by the probe p13E-11. Hum Mol Genet. 1993; 2:1673-1678.

11. Snider L, Geng LN, Lemmers RJ, Kyba M, Ware CB, Nelson AM, Tawil R, Filippova GN, van der Maarel SM, Tapscott SJ, Miller DG. Facioscapulohumeral dystrophy: incomplete suppression of a retrotransposed gene. PLoS Genet. 2010; doi: 10.1371/journal.pgen.1001181.
12. Geng LN, Yao Z, Snider L, Fong AP, Cech JN, Young JM, van der Maarel SM, Ruzzo WL, Gentleman RC, Tawil R, Tapscott SJ. DUX4 activates germline genes, retroelements, and immune mediators: implications for facioscapulohumeral dystrophy. Dev Cell. 2012; 22:38-51.

13. Kowaljow V, Marcowycz A, Ansseau E, Conde CB, Sauvage S, Matteotti C, Arias C, Corona ED, Nunez NG, Leo O, Wattiez R, Figlewicz D, Laoudj-Chenivesse D, et al. The DUX4 gene at the FSHD1A locus encodes a proapoptotic protein. Neuromuscul Disord. 2007; 17:611-623.

14. Bosnakovski D, Xu Z, Gang EJ, Galindo CL, Liu M, Simsek T, Garner HR, Agha-Mohammadi S, Tassin A, Coppee F, Belayew A, Perlingeiro RR, Kyba M. An isogenetic myoblast expression screen identifies DUX4mediated FSHD-associated molecular pathologies. The EMBO J. 2008; 27:2766-2779.

15. Corona ED, Jacquelin D, Gatica L, Rosa AL. Multiple protein domains contribute to nuclear import and cell toxicity of DUX4, a candidate pathogenic protein for facioscapulohumeral muscular dystrophy. PLoS ONE. 2013; 8:e75614.

16. Vanderplanck C, Ansseau E, Charron S, Stricwant N, Tassin A, Laoudj-Chenivesse D, Wilton SD, Coppee F, Belayew A. The FSHD Atrophic Myotube Phenotype Is Caused by DUX4 Expression. PLoS ONE. 2011; doi: 10.1371/journal.pone.0026820.

17. Snider L, Asawachaicharn A, Tyler AE, Geng LN, Petek LM, Maves L, Miller DG, Lemmers RJ, Winokur ST, Tawil R, van der Maarel SM, Filippova GN, Tapscott SJ. RNA transcripts, miRNA-sized fragments and proteins produced from D4Z4 units: new candidates for the pathophysiology of facioscapulohumeral dystrophy. Hum Mol Genet. 2009; 18:2414-2430.

18. Wuebbles RD, Long SW, Hanel ML, Jones PL. Testing the effects of FSHD candidate gene expression in vertebrate muscle development. Int J Clin Exp Pathol. 2010; $3: 386-400$.

19. Wallace LM, Garwick SE, Mei W, Belayew A, Coppee F, Ladner KJ, Guttridge D, Yang J, Harper SQ. DUX4, a candidate gene for facioscapulohumeral muscular dystrophy, causes p53-dependent myopathy in vivo. Ann Neurol. 2010; 69:540-552.

20. Mitsuhashi H, Mitsuhashi S, Lynn-Jones T, Kawahara G, Kunkel LM. Expression of DUX4 in zebrafish development recapitulates facioscapulohumeral muscular dystrophy. Hum Mol Genet. 2013; 22:568-577.

21. Krom YD, Thijssen PE, Young JM, den Hamer B, Balog J, Yao Z, Maves L, Snider L, Knopp P, Zammit PS, Rijkers T, van Engelen BG, Padberg GW, et al. Intrinsic epigenetic regulation of the $\mathrm{D} 4 \mathrm{Z} 4$ macrosatellite repeat in a transgenic mouse model for FSHD. PLoS Genet. 2013; doi: 10.1371/ journal.pgen.1003415.

22. Ansseau E, Laoudj-Chenivesse D, Marcowycz A, Tassin A, Vanderplanck C, Sauvage S, Barro M, Mahieu I, Leroy A, 
Leclercq I, Mainfroid V, Figlewicz D, Mouly V, et al. DUX4c is up-regulated in FSHD. It induces the MYF5 protein and human myoblast proliferation. PLoS ONE. 2009; doi: 10.1371/journal.pone.0007482.

23. Bosnakovski D, Lamb S, Simsek T, Xu Z, Belayew A, Perlingeiro R, Kyba M. DUX4c, an FSHD candidate gene, interferes with myogenic regulators and abolishes myoblast differentiation. Exp Neurol. 2008; 214:87-96.

24. Geng LN, Tyler AE, Tapscott SJ. Immunodetection of human double homeobox 4. Hybridoma (Larchmt). 2011; 30:125-130.

25. DeVries ME, Kelvin AA, Xu L, Ran L, Robinson J, Kelvin DJ. Defining the origins and evolution of the chemokine/chemokine receptor system. J Immunol. 2006; 176:401-415.

26. Griffith JW, Sokol CL, Luster AD. Chemokines and chemokine receptors: positioning cells for host defense and immunity. Annu Rev Immunol. 2014; 32:659-702.

27. Baggiolini M. Chemokines, leukocyte traffic. Nature. 1998; 392:565-568.

28. Sokol CL, Luster AD. The chemokine system in innate immunity. Cold Spring Harb Perspect Biol. 2015; 7.

29. Esche C, Stellato C, Beck LA. Chemokines: key players in innate and adaptive immunity. J Invest Dermatiol. 2005; 125:615-628.

30. Moser B, Loetscher P. Lymphocyte traffic control by chemokines. Nat Immunol. 2001; 2:123-128.

31. Le Y, Zhou Y, Iribarren P, Wang J. Chemokines and chemokine receptors: their manifold roles in homeostasis and disease. Cell Mol Immunol. 2004; 1:95-104.

32. Rossi D, Zlotnik A. The biology of chemokines and their receptors. Annu Rev Immunol. 2000; 18:217-242.

33. Nagasawa T, Kikutani H, Kishimoto T. Molecular cloning and structure of a pre-B-cell growth-stimulating factor. Proc Natl Acad Sci USA. 1994; 91:2305-2309.

34. Feng Y, Broder CC, Kennedy PE, Berger EA. HIV-1 entry cofactor: functional cDNA cloning of a seventransmembrane, G protein-coupled receptor. Science. 1996; 272:872-877.

35. Raz E, Mahabaleshwar H. Chemokine signaling in embryonic cell migration: a fisheye view. Development. 2009; 136:1223-1229.

36. Belperio JA, Keane MP, Arenberg DA, Addison CL, Ehlert JE, Burdick MD, Strieter RM. CXC chemokines in angiogenesis. J Leuk Biol. 2000; 68:1-8.

37. Strieter RM, Burdick MD, Gomperts BN, Belperio JA, Keane MP. CXC chemokines in angiogenesis. Cytokine Growth Factor Rev. 2005; 16:593-609.

38. Lewellis SW, Knaut H. Attractive guidance: how the chemokine SDF1/CXCL12 guides different cells to different locations. Semin. Cell Dev Biol. 2012; 23:333-340.

39. Nagasawa T. CXC chemokine ligand 12 (CXCL12) and its receptor CXCR4. J Mol Med. 2014; 92:433-439.
40. Martins-Green M, Petreaca M, Wang L. Chemokines and Their Receptors Are Key Players in the Orchestra That Regulates Wound Healing. Adv Wound Care. 2013; 2:327-347.

41. Sharma M, Afrin F, Satija N, Tripathi RP, Gangenahalli GU. Stromal-derived factor-1/CXCR4 signaling: indispensable role in homing and engraftment of hematopoietic stem cells in bone marrow. Stem Cell Dev. 2011; 20:933-946.

42. Marquez-Curtis LA, Janowska-Wieczorek A. Enhancing the migration ability of mesenchymal stromal cells by targeting the SDF-1/CXCR4 axis. Biomed Res Int. 2013; 2013:561098.

43. Liu ZJ, Zhuge Y, Velazquez OC. Trafficking and differentiation of mesenchymal stem cells. J Cell Biochem. 2009; 106:984-991.

44. Nombela-Arrieta C, Ritz J, Silberstein LE. The elusive nature and function of mesenchymal stem cells. Nat Rev Mol Cell Biol. 2011; 12:126-131.

45. Bhakta S, Hong P, Koc O. The surface adhesion molecule CXCR4 stimulates mesenchymal stem cell migration to stromal cell-derived factor-1 in vitro but does not decrease apoptosis under serum deprivation. Cardiovasc Revasc Med. 2006; 7:19-24.

46. Ponte AL, Marais E, Gallay N, Langonne A, Delorme B, Herault $\mathrm{O}$, Charbord $\mathrm{P}$, Domenech J. The in vitro migration capacity of human bone marrow mesenchymal stem cells: comparison of chemokine and growth factor chemotactic activities. Stem cells (Dayton, Ohio). 2007; 25:1737-1745.

47. Sharma V, Harafuji N, Belayew A, Chen YW. DUX4 Differentially Regulates Transcriptomes of Human Rhabdomyosarcoma and Mouse C2C12 Cells. PLoS ONE. 2013; doi: 10.1371/journal.pone.0064691.

48. Homma S, Beermann ML, Boyce FM, Miller JB. Expression of FSHD-related DUX4-FL alters proteostasis and induces TDP-43 aggregation. Ann Clin Transl Neurol. $2015 ; 2: 151-166$.

49. Dandapat A, Hartweck LM, Bosnakovski D, Kyba M. Expression of the human FSHD-linked DUX4 gene induces neurogenesis during differentiation of murine embryonic stem cells. Stem Cells Dev. 2013; 22:2440-2448.

50. Yao Z, Snider L, Balog J, Lemmers RJ, Van Der Maarel SM, Tawil R, Tapscott SJ. DUX4-induced gene expression is the major molecular signature in FSHD skeletal muscle. Hum Mol Genet. 2014; 23:5342-5352.

51. Xu H, Wang Z, Jin S, Hao H, Zheng L, Zhou B, Zhang W, Lv H, Yuan Y. Dux4 induces cell cycle arrest at G1 phase through upregulation of $\mathrm{p} 21$ expression. Biochem Biophys Res Commun. 2014; 446:235-240.

52. Broxmeyer HE. Regulation of hematopoiesis by chemokine family members. Int J Hematol. 2001; 74:9-17.

53. Burger JA, Kipps TJ. CXCR4: a key receptor in the crosstalk between tumor cells and their microenvironment. Blood. 2006; 107:1761-1767.

54. Molyneaux KA, Zinszner H, Kunwar PS, Schaible K, Stebler J, Sunshine MJ, O’Brien W, Raz E, Littman D, 
Wylie C, Lehmann R. The chemokine SDF1/CXCL12 and its receptor CXCR4 regulate mouse germ cell migration and survival. Development. 2003; 130:4279-4286.

55. Lazarini F, Tham TN, Casanova P, Arenzana-Seisdedos F, Dubois-Dalcq M. Role of the alpha-chemokine stromal cellderived factor (SDF-1) in the developing and mature central nervous system. Glia. 2003; 42:139-148.

56. Tachibana K, Hirota S, Iizasa H, Yoshida H, Kawabata K, Kataoka Y, Kitamura Y, Matsushima K, Yoshida N, Nishikawa S, Kishimoto T, Nagasawa T. The chemokine receptor CXCR4 is essential for vascularization of the gastrointestinal tract. Nature. 1998; 393:591-594.

57. Odemis V, Lamp E, Pezeshki G, Moepps B, Schilling K, Gierschik P, Littman DR, Engele J. Mice deficient in the chemokine receptor CXCR4 exhibit impaired limb innervation and myogenesis. Mol Cell Neurosci. 2005; 30:494-505.

58. Vasyutina E, Stebler J, Brand-Saberi B, Schulz S, Raz E, Birchmeier C. CXCR4 and Gab1 cooperate to control the development of migrating muscle progenitor cells. Genes Dev. 2005; 19:2187-2198.

59. Yusuf F, Rehimi R, Morosan-Puopolo G, Dai F, Zhang X, Brand-Saberi B. Inhibitors of CXCR4 affect the migration and fate of CXCR4+ progenitors in the developing limb of chick embryos. Dev Dyn. 2006; 235:3007-3015.

60. Masyuk M, Abduelmula A, Morosan-Puopolo G, Odemis V, Rehimi R, Khalida N, Yusuf F, Engele J, Tamamura H, Theiss C, Brand-Saberi B. Retrograde migration of pectoral girdle muscle precursors depends on CXCR4/SDF-1 signaling. Histochem Cell Biol. 2014.

61. Ratajczak MZ, Majka M, Kucia M, Drukala J, Pietrzkowski Z, Peiper S, Janowska-Wieczorek A. Expression of functional CXCR4 by muscle satellite cells and secretion of SDF-1 by muscle-derived fibroblasts is associated with the presence of both muscle progenitors in bone marrow and hematopoietic stem/progenitor cells in muscles. Stem cells (Dayton, Ohio). 2003; 21:363-371.

62. Clapp J, Mitchell LM, Bolland DJ, Fantes J, Corcoran AE, Scotting PJ, Armour JA, Hewitt JE. Evolutionary conservation of a coding function for D4Z4, the tandem DNA repeat mutated in facioscapulohumeral muscular dystrophy. Am. J Hum Genet. 2007; 81:264-279.

63. Kawazu M, Yamamoto G, Yoshimi M, Yamamoto K, Asai T, Ichikawa M, Seo S, Nakagawa M, Chiba S, Kurokawa M, Ogawa S. Expression profiling of immature thymocytes revealed a novel homeobox gene that regulates doublenegative thymocyte development. J Immunol. 2007; 179:5335-5345.

64. Wu SL, Tsai MS, Wong SH, Hsieh-Li HM, Tsai TS, Chang WT, Huang SL, Chiu CC, Wang SH. Characterization of genomic structures and expression profiles of three tandem repeats of a mouse double homeobox gene: Duxbl. Dev Dyn. 2010; 239:927-940.

65. Wu SL, Li GZ, Chou CY, Tsai MS, Chen YP, Li CJ, Liou GG, Chang WW, Chen SL, Wang SH. Double homeobox gene, Duxbl, promotes myoblast proliferation and abolishes myoblast differentiation by blocking MyoD transactivation. Cell Tissue Res. 2014; 358:551-566.

66. Dandapat A, Bosnakovski D, Hartweck LM, Arpke RW, Baltgalvis KA, Vang D, Baik J, Darabi R, Perlingeiro RC, Hamra FK, Gupta K, Lowe DA, Kyba M. Dominant lethal pathologies in male mice engineered to contain an X-linked DUX4 transgene. Cell Rep. 2014; 8:1484-1496.

67. Dixit M, Ansseau E, Tassin A, Winokur S, Shi R, Qian H, Sauvage S, Matteotti C, van Acker AM, Leo O, Figlewicz D, Barro M, Laoudj-Chenivesse D, et al. DUX4, a candidate gene of facioscapulohumeral muscular dystrophy, encodes a transcriptional activator of PITX1. Proc Natl Acad Sci USA. 2007; 104:18157-18162.

68. Dmitriev P, Stankevicins L, Ansseau E, Petrov A, Barat A, Dessen P, Robert T, Turki A, Lazar V, Labourer E, Belayew A, Carnac G, Laoudj-Chenivesse D, et al. Defective regulation of microRNA target genes in myoblasts from facioscapulohumeral dystrophy patients. J Biol Chem. 2013; 288:34989-35002.

69. Odemis V, Boosmann K, Dieterlen MT, Engele J. The chemokine SDF1 controls multiple steps of myogenesis through atypical PKCzeta. J Cell Sci. 2007; 120:4050-4059.

70. Brzoska E, Kowalewska M, Markowska-Zagrajek A, Kowalski K, Archacka K, Zimowska M, Grabowska I, Czerwinska AM, Czarnecka-Gora M, Streminska W, Janczyk-Ilach K, Ciemerych MA. Sdf-1 (CXCL12) improves skeletal muscle regeneration via the mobilisation of Cxcr4 and CD34 expressing cells. Biol Cell. 2012; 104:722-737.

71. Melchionna R, Di Carlo A, De Mori R, Cappuzzello C, Barberi L, Musaro A, Cencioni C, Fujii N, Tamamura H, Crescenzi M, Capogrossi MC, Napolitano M, Germani A. Induction of myogenic differentiation by SDF-1 via CXCR4 and CXCR7 receptors. Muscle Nerve. 2010; 41:828-835.

72. Arahata K, Ishihara T, Fukunaga H, Orimo S, Lee JH, Goto K, Nonaka I. Inflammatory response in facioscapulohumeral muscular dystrophy (FSHD): immunocytochemical and genetic analyses. Muscle Nerve. 1995; 2:S56-66.

73. Werner L, Guzner-Gur H, Dotan I. Involvement of CXCR4/ CXCR7/CXCL12 Interactions in Inflammatory bowel disease. Theranostics. 2013; 3:40-46.

74. Wald O, Pappo O, Safadi R, Dagan-Berger M, Beider K, Wald H, Franitza S, Weiss I, Avniel S, Boaz P, Hanna J, Zamir G, Eid A, et al. Involvement of the CXCL12/CXCR4 pathway in the advanced liver disease that is associated with hepatitis C virus or hepatitis B virus. Eur J Immunol. 2004; 34:1164-1174.

75. Hummel S, Van Aken H, Zarbock A. Inhibitors of CXC chemokine receptor type 4: putative therapeutic approaches in inflammatory diseases. Curr Opin Immunology. 2014; 21:29-36.

76. Lang DS, Marwitz S, Kugler C, Reinmuth N, Vollmer E, Zabel P, Reck M, Goldmann T. Double Homeobox Protein DUX4 in the Human Lung: Expression under Normal and Pathological Conditions. GJMR-C. 2014; 2:1-9. 
77. Katargin AN, Pavlova LS, Kisseljov FL, Kisseljova NP. Hypermethylation of genomic $3.3-\mathrm{kb}$ repeats is frequent event in HPV-positive cervical cancer. BMC Med Genomics. 2009; 2:30.

78. Yasuda T, Tsuzuki S, Kawazu M, Hayakawa F, Kojima S, Ueno T, Imoto N, Kohsaka S, Kunita A, Doi K, Sakura T, Yujiri T, Kondo E, et al. Recurrent DUX4 fusions in B cell acute lymphoblastic leukemia of adolescents and young adults. Nat Genet. 2016; 48:569-74.

79. Sirvent N, Trassard M, Ebran N, Attias R, Pedeutour F. Fusion of EWSR1 with the DUX4 facioscapulohumeral muscular dystrophy region resulting from $\mathrm{t}(4 ; 22)(\mathrm{q} 35 ; \mathrm{q} 12)$ in a case of embryonal rhabdomyosarcoma. Cancer Genet Cytogenet. 2009; 195:12-18.

80. Kawamura-Saito M, Yamazaki Y, Kaneko K, Kawaguchi N, Kanda H, Mukai H, Gotoh T, Motoi T, Fukayama M, Aburatani H, Takizawa T, Nakamura T. Fusion between CIC and DUX4 up-regulates PEA3 family genes in Ewinglike sarcomas with $\mathrm{t}(4 ; 19)(\mathrm{q} 35 ; \mathrm{q} 13)$ translocation. Hum Mol Genet. 2006; 15:2125-2137.

81. Graham C, Chilton-MacNeill S, Zielenska M, Somers GR. The CIC-DUX4 fusion transcript is present in a subgroup of pediatric primitive round cell sarcomas. Hum Pathol. 2012; 43:180-189.

82. Cadieux B, Ching TT, VandenBerg SR, Costello JF. Genomewide hypomethylation in human glioblastomas associated with specific copy number alteration, methylenetetrahydrofolate reductase allele status, and increased proliferation. Cancer Res. 2006; 66:8469-8476.

83. Paz MF, Wei S, Cigudosa JC, Rodriguez-Perales S, Peinado MA, Huang TH, Esteller M. Genetic unmasking of epigenetically silenced tumor suppressor genes in colon cancer cells deficient in DNA methyltransferases. Hum Mol Genet. 2003; 12:2209-2219.

84. Sun Z, Wang S, Zhao RC. The roles of mesenchymal stem cells in tumor inflammatory microenvironment. J Hematol Oncol. 2014; 7:14.

85. Yagi H, Kitagawa Y. The role of mesenchymal stem cells in cancer development. Front Genet. 2013; 4:261.

86. Domanska UM, Kruizinga RC, Nagengast WB, TimmerBosscha H, Huls G, de Vries EG, Walenkamp AM. A review on CXCR4/CXCL12 axis in oncology: no place to hide. Eur J Cancer. 2013; 49:219-230.
87. Santoni M, Bracarda S, Nabissi M, Massari F, Conti A, Bria E, Tortora G, Santoni G, Cascinu S. CXC and CC chemokines as angiogenic modulators in nonhaematological tumors. Biomed Res Int. 2014; 2014:768758.

88. Lourenco S, Teixeira VH, Kalber T, Jose RJ, Floto RA, Janes SM. Macrophage migration inhibitory factor-CXCR4 is the dominant chemotactic axis in human mesenchymal stem cell recruitment to tumors. J Immunol. 2015; 194:3463-3474.

89. Murphy PM. Chemokines and the molecular basis of cancer metastasis. New Engl J Med. 2001; 345:833-835.

90. Zhu CH, Mouly V, Cooper RN, Mamchaoui K, Bigot A, Shay JW, Di Santo JP, Butler-Browne GS, Wright WE. Cellular senescence in human myoblasts is overcome by human telomerase reverse transcriptase and cyclindependent kinase 4: consequences in aging muscle and therapeutic strategies for muscular dystrophies. Aging cell. 2007; 6:515-523.

91. Barro M, Carnac G, Flavier S, Mercier J, Vassetzky Y, Laoudj-Chenivesse D. Myoblasts from affected and nonaffected FSHD muscles exhibit morphological differentiation defects. J Cel Mol Med. 2010; 14:275-289.

92. Kiseleva EV, Chermnykh ES, Vorotelyak EA, Volozhinb AI, Vasiliev AV, Terskikh VV. Differentiation capacity of stromal fibroblast-like cells from human bone marrow, adipose tissue, hair follicle dermal papilla and derma. Cell Tissue Biol. 2009; 3:42-49.

93. Ward IM, Chen J. Histone H2AX is phosphorylated in an ATR-dependent manner in response to replicational stress. J Biol Chem. 2001; 47759-47762.

94. Malathi K, Xiao Y, Mitchell AP. Catalytic roles of yeast GSK3beta/shaggy homolog Rim11p in meiotic activation. Genetics. 1999; 153:1145-1152.

95. Muller PY, Janovjak H, Miserez AR, Dobbie Z. Processing of gene expression data generated by quantitative real-time RTPCR. BioTechniques. 2002; 32:1372-1374, 1376, 1378-1379. 